\title{
Variability in sepiolite: Diffraction studies
}

\section{Manuel Sánchez del Río, ${ }^{1, *}$ Emilia García-Romero, ${ }^{2,6}$ Mercedes SuÁrez, ${ }^{3}$ IVÁn da Silva, Luis Fuentes-Montero, ${ }^{5}$ ANd GeMa Martínez-Criado ${ }^{1}$}

\author{
${ }^{1}$ European Synchrotron Radiation Facility, 6 rue Jules Horowitz, 38000 Grenoble, France \\ ${ }^{2}$ Departamento de Cristalografía y Mineralogía, Universidad Complutense de Madrid, 28040 Madrid, Spain \\ ${ }^{3}$ Departamento de Geología. Universidad de Salamanca, Patio de Escuelas 1, 37008 Salamanca, Spain \\ ${ }^{4}$ Spline Spanish CRG Beamline at the European Synchrotron Radiation Facility, 6 rue Jules Horowitz, 38000 Grenoble, France \\ ${ }^{5}$ Institut Laue-Langevin, 6 rue Jules Horowitz, 38000 Grenoble, France \\ ${ }^{6}$ Instituto de Geociencias (UCM-CSIC), 28040 Madrid, Spain
}

\begin{abstract}
Twenty sepiolites of known composition from different origins were analyzed to quantify the variability in structural parameters and its possible relationships with composition and morphology. Morphology SEM analyses led to classify the sepiolites into several groups, beyond the two simple macroscopic or clay groups. X-ray powder diffraction with synchrotron light was used to discuss the variability of the $a$ and $b$ cell parameters with the nature of the cations and occupancy of the octahedral shell. Rietveld refinement using the ideal sepiolite model is performed on sepiolites at two temperatures: $225{ }^{\circ} \mathrm{C}$ (for zeolitically dehydrated sepiolite) and $25{ }^{\circ} \mathrm{C}$ (for hydrated ambient sepiolite). The latter permitted to locate ca. six molecules of the zeolitic $\mathrm{H}_{2} \mathrm{O}$ within the tunnels.

A few samples were selected to evaluate the feasibility and potential of single-crystal diffraction methods: X-ray microdiffraction and electron diffraction. The macroscopic sepiolites gave wellstructured and rich X-ray fiber diffraction patterns, in excellent agreement with ab initio simulations. High-quality single-crystal electron diffraction patterns for three axis zones are indexed and compared with simulations. The experimental and modeling results for X-ray microdiffraction and electron diffraction open a new path for quantitative crystallography on sepiolite and other fibrous clays from the sepiolite-palygorskite group.
\end{abstract}

Keywords: Sepiolite, X-ray diffraction, Rietveld, 2D diffraction pattern, SEM, TEM, SAED, ab initio simulations

\section{INTRODUCTION}

Sepiolite is a fibrous clay mineral that differs from laminar clays by having tunnels in its structure, resulting from the inversion of apical $\mathrm{O}$ atoms in the tetrahedral sheets every eighth octahedral positions (forming tunnels with cross section of about $4 \times 11 \AA^{2}$ that run parallel to the $c$ axis). These tunnels can hold zeolitic $\mathrm{H}_{2} \mathrm{O}$ as well as other small molecules. Sepiolite is a trioctahedral phyllosilicate, with all octahedral positions occupied by $\mathrm{Mg}$ in the "ideal" sepiolite (see Fig. 1) with theoretical structural formula $\mathrm{Si}_{12} \mathrm{O}_{30} \mathrm{Mg}_{8}(\mathrm{OH})_{4}\left(\mathrm{OH}_{2}\right)_{4} \cdot 8 \mathrm{H}_{2} \mathrm{O}$. The physicochemical properties of sepiolite ultimately depend on the crystalline structure at atomic scale. The tunnels in the crystal cell induce a fibrous morphology at a microscopic (and sometimes macroscopic) level, which in turn is responsible of the great absorptive power and the good rheological properties of this mineral.

The possible correlation between crystalline structure and macroscopic properties adds interest for studying this clay at

\footnotetext{
*E-mail: srio@esrf.eu
}

the microscopic level. Two possible crystallographic models for sepiolite were proposed by (Nagy and Bradley 1955). Later, the orthorhombic model with space group Pncn proposed by Brauner and Preisinger (1956) and Preisinger (1959) was generally accepted. However, the composition of sepiolite may vary depending on the origin, formation conditions, chemical environment, etc., differing from the theoretical model. This can be manifested in structural variations that cause modifications in the diffraction patterns, in particular shifts in the peak positions and changes in peak intensities.

Sepiolite like all clays usually exhibit a fine-grained and poorly crystalline nature, therefore many details of the crystalline structure are still not well known. Rietveld refinement is not frequently used for clay analysis, because of the crystal complexity, low crystallinity, and small particle size. Moreover, the agreement of most authors in the crystalline structure of sepiolite, the fact that different sepiolites present different cell parameters, and the nonexistence of sepiolite single crystals large enough for accurate single-crystal diffraction, may explain the lack of crystallographic refinements of the sepiolite structure until very recently. Post et al. (2007) performed a Rietveld 

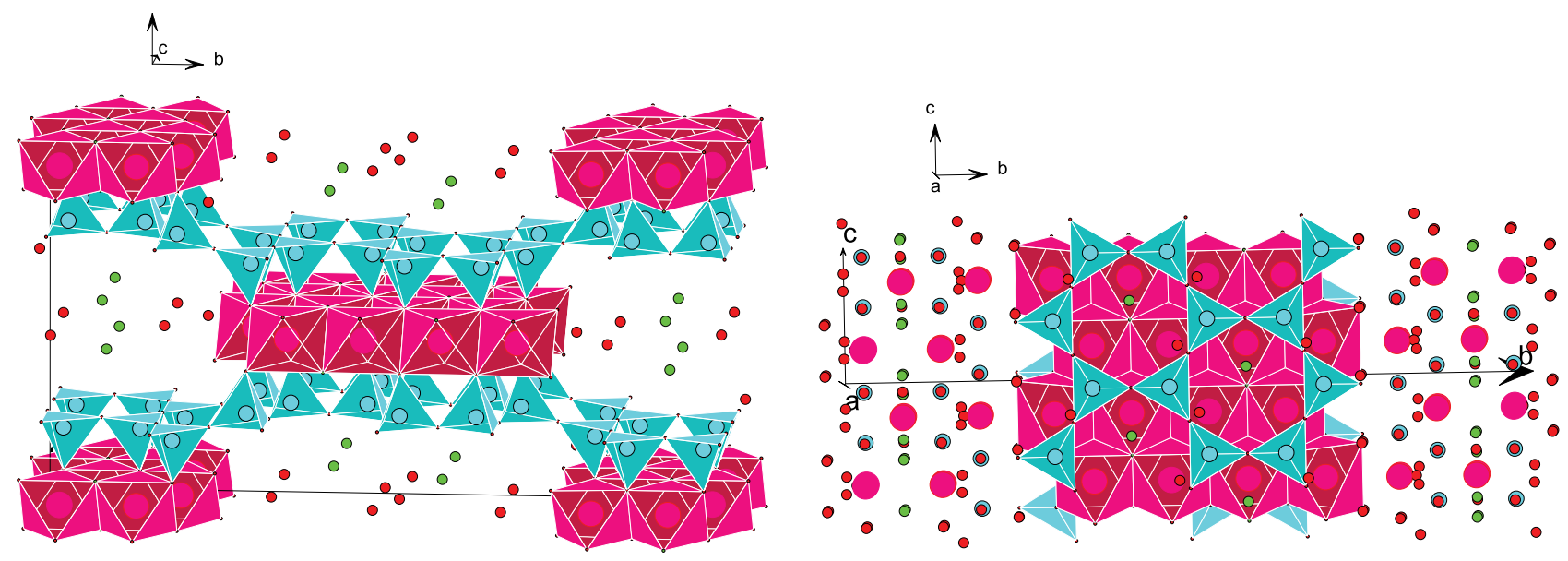

FIGURE 1. Schematic view of a $1 \times 1 \times 2$ supercell of ideal sepiolite. Left graphs represent a perspective view and right graphs show a projection onto the (b-c) plane. Octahedra always have an $\mathrm{Mg}$ atom in the center in sepiolite.

analysis of the structure of a sepiolite sample from Durango (New Mexico, U.S.A.) using synchrotron radiation data. They obtained high-quality real-time temperature-resolved data evidencing the dehydration and decomposition of sepiolite up to $600{ }^{\circ} \mathrm{C}$. These techniques are sensitive to small effects like the existence and positioning of zeolitic $\mathrm{H}_{2} \mathrm{O}$, hardly observable by conventional X-ray diffraction.

Regarding the morphology of sepiolite, two main groups may be distinguished according to the fiber size: clay-sepiolite and macroscopic-sepiolite. Sepiolite can be found in different environments, like marine (Yalcin and Bozkaya 1995), sedimentary and hydrothermal. The latter implies higher temperature and more homogeneous compositions of the precursor solution than the former, and consequently better crystals may be formed (in terms of composition and crystallinity). Micro-X-ray diffraction reveals non-uniformities such as fiber orientation, large variations in the grain size, anisotropy in the orientation of the fibers, and poor crystallinity. Fibrous macroscopic sepiolites have been studied in several works (Arranz et al. 2008; Bastida et al. 1994; Callen 1984; Yalcin and Bozkaya 2004). An objective of the present work is to reveal differences in the diffractions patterns of sepiolites belonging to these groups, suggesting morphological classifications.

The compositional variability of sepiolite may also be reflected in the crystalline structure. A modification of some cell parameters as a function of the octahedral occupation and nature of the substituted atoms could be expected, as found for palygorskite (Chryssikos et al. 2009; Suárez et al. 2007). In this work, we performed powder diffraction analyses based on synchrotron radiation on 20 samples characterized chemically by analytical electron microscopy (AEM) and morphologically by scanning electron microscopy (SEM). Moreover, a few samples with special characteristics were selected for further detailed studies by X-ray powder diffraction Rietveld refinement, synchrotron X-ray microdiffraction, and electron diffraction (ED). The last two techniques, used on samples with particular characteristics and supported by computer simulations, were used to explore potential ways to approach quantitative single-crystal diffraction in sepiolite and similar minerals.

\section{MATERIALS, COMPOSITION, AND EXPERIMENTAL METHODS}

The collection of 20 sepiolites studied here contains samples from very different areas worldwide and are listed in Table 1, including the labels used to reference them hereafter. They come from Africa (NAM, SOM), China (HEN, LIE, NEI, XIX), Bosnia (BOS), Finland (FIN), Italy (MON), Norway (NOR), Spain (VIC, VAL, YUN, BAT, MAR), Turkey (MER, TPO), and the U.S.A. (SAN, GRA, NEV). Some samples have been collected in situ and have been the object of other works (García-Romero and Suárez 2010), while the others have been obtained from researchers, companies that exploit mineral deposits, as well as from mineral collections. Samples were selected taking into account their high content in sepiolite, but other phases have been occasionally found in different quantities, as shown in Table 1. There are some samples with interesting particularities: Meerschaum (Turkey) (Alkan et al. 2007) is well known for historical reasons and for being the preferred material for smoking pipes manufacturers, Vallecas (Spain) has been used as a reference in several papers (Casal et al. 2001; Gómez-Avilés et al. 2010; Sanchez-Martin et al. 2006; Vico and Acebal 2006) as well as Batallones (Legido et al. 2007), YUN (Molina-Sabio et al. 2001), or NEV (Pardo et al. 2009) and Norway is the best crystallized sepiolite in our collection, which will be discussed in detail.

In analytical chemistry, the standard methods used to measure the structural formula of sepiolite give an average elemental composition over the whole sample. As a consequence, errors are introduced because of the unavoidable presence of impurities, usually containing the same type of elements as sepiolite. A microcharacterization using analytical electron microscopy (AEM) by means of a transmission

TABLE 1. List of the sepiolite samples, including labeling, origin, approximated purity (from XRD data), and other phases identified

\begin{tabular}{lccc}
\hline Label & Provenance & Purity (\%) & Other phases (traces) \\
\hline BAT & Batallones, Madrid, Spain & 100 & \\
BOS & Bosnia & 90 & Magnesite \\
FIN & Finlandia & 60 & Talc \\
GRA & Grant County, NM, U.S.A. & 100 & \\
HEN & Henan, China & $\sim 100$ & (Talc) \\
LIE & Lieyang, China & 95 & Talc \\
MAR & Mara, Zaragoza, Spain & $\sim 100$ & (Smectite) \\
MER & Meerschaum, Eskisehir, Turkey & 100 & \\
MON & Monferrato, Piemont, Italy & 100 & \\
NAM & Namibia & 85 & Calcite \\
NEI & Neixiang, China & 100 & \\
NEV & NV, U.S.A. & 90 & Quartz, Feldspar \\
NOR & Fauske, Noraland, Noruega & 100 & \\
SAN & Santa Cruz County, CA, U.S.A. & 80 & Calcite \\
SOM & Somalia & 80 & Quartz (Palygorskite) \\
TPO & Polatti, Turkey & $\sim 100$ & (Dolomite) \\
VAL & Vallecas, Madrid, Spain & 100 & \\
VIC & Vicalvaro, Madrid, Spain & 100 & \\
XIX & Xixia, Henan, China & $\sim 100$ & (Smectite) \\
YUN & Yunclillos, Toledo, Spain & 100 & \\
\hline
\end{tabular}


electron microscope (TEM), permits a selective analysis on selected sepiolite fibers. The structural formulas for the sepiolite were calculated from the ideal structure, normalized to 32 negative charges. Oxygen was not measured quantitatively. All the $\mathrm{Fe}$ present was considered as $\mathrm{Fe}^{3+}$, thus ignoring the possible existence of $\mathrm{Fe}^{2+}$ (usually very small), which cannot be discriminated by this technique. Results are summarized in Table 2

The morphology of the samples was studied by using a field emission gun scanning electron microscope (FEG-SEM) and also a transmission electron microscopy (TEM). FEG-SEM observations were done with a JEOL JSM-6330F (field emission scanning electron microscope) operating at $10 \mathrm{kV}$. Prior to FEG-SEM examination, freshly fractured surfaces of representative samples were air-dried and coated with Au under vacuum. TEM observations were performed by depositing a drop of suspension containing diluted samples of great purity on a microscopic grid with collodion. A JEOL $2000 \mathrm{FX}$ microscope equipped with a double-tilt sample holder (up to a maximum of $\pm 45^{\circ}$ ) at an acceleration voltage of $200 \mathrm{kV}$, with 0.5 $\mathrm{mm} \zeta$-axis displacement and $0.31 \mathrm{~nm}$ point-to-point resolution was used. This TEM microscope incorporates an OXFORD ISIS energy-dispersive X-ray spectrometer $(136 \mathrm{eV}$ resolution at $5.39 \mathrm{keV})$, which was used for quantitative chemical analysis (Table 2). The TEM microscope was also used for structural analysis by selected area electron diffraction (SAED).

High-resolution X-ray powder diffraction patterns were collected at the Spanish beamline BM25A at the European Synchrotron Radiation Facility (ESRF). The recorded data comes from different experimental runs, using always a photon wavelength around $0.8 \AA(\sim 15 \mathrm{keV})$. Powdered samples were placed inside a 1 $\mathrm{mm}$ diameter capillary, which was rotated during exposure. The data were collected in a continuous $2 \theta$-scan mode from 3 to $20^{\circ}$ with an angular step of $0.02^{\circ}$. The background signal was removed using a multi-strip algorithm implemented in XOP/XPLOT (Sánchez del Río and Dejus 2004). Peak positions were obtained by fitting the experimental data vs. angle ( $2 \theta)$ with an asymmetric pseudo-Voigt function due to axial divergence (Finger et al. 1994), by means of a LevenbergMarquardt fitting algorithm available in the WinPLOTR software (Roisnel and Rodriguez-Carvajal 2000). The diffraction patterns for Rietveld refinements were collected in a continuous $2 \theta$-scan mode from 2 to $80^{\circ}$ at a wavelength of 0.8263 $\AA$, with an angular step of $0.02^{\circ}$. They were measured at two temperatures: room temperature for hydrated sepiolite, and $225^{\circ} \mathrm{C}$ for zeolitically dehydrated sepiolite. The samples were heated by a Cyberstar gas blower, driven by a Eurotherm $902 \mathrm{~b}$ temperature controller. Rietveld analysis was performed using the FullProf software suite (Rodriguez-Carvajal 1993). Lanthanum hexaboride ( $\mathrm{LaB}_{6}$, NIST, Standard Reference Material 660a) was used to determine the instrumental function.

Synchrotron Radiation microdiffraction experiments were performed at the ESRF ID18F beamline (Somogyi et al. 2001). A monochromatic X-ray beam (14400 $\mathrm{eV}$ or $0.861 \AA$ ) was focused to a beam diameter of about $5 \mu \mathrm{m}$ using aluminum compound refractive lenses. A Mar-Research CCD detector $(2048 \times 2048$ pixels $)$ collected X-ray diffraction patterns with a variable exposure time up to $120 \mathrm{~s}$. The diffraction images were calibrated using as reference alumina compound for refining the geometrical parameters (intersection point of the beam with the detector, and position of the sample). Using these parameters, the 1D conventional diffraction patterns (intensity vs. $2 \theta$ angle) were obtained by azimuthally integrating the $2 \mathrm{D}$ patterns. Calibration, azimuthal integration, and further analysis were performed using the XOP/XPLOT2D software.

\section{RESULTS AND DISCUSSION}

The chemical composition of the samples was obtained using AEM/TEM point analysis on individual sepiolite particles (García-Romero and Suárez 2010). The resulting structural formulas (Table 2) indicate that the tetrahedral substitution in these natural sepiolites is low, i.e., $\leq 0.32 \mathrm{Al}$ atoms for 12 tetrahedral sites. Indeed, some sepiolites samples present compositions very close to the ideal value (MER 11.99, TPO 12.00, LIE 12.00).

The atomic contents of the octahedral sheet vary from one sample to another, both for the total occupation number $\Sigma o(7.02$ [LIE] $<\Sigma_{0}<7.85$ [TPO]) and for the substituted atomic type $(0.02$ [SAN] $<$ [Al] $<1.18$ [LIE], 0.01 [MER] $<[\mathrm{Fe}]<0.61$ [FIN]). In fact, a few samples exhibit extreme compositions in the octahedral sheet because of a large Al content (like 1.18 for LIE or 0.68 for BAT) and/or $\mathrm{Fe}^{3+}$ content ( 0.61 for FIN or 0.32 for LIE). MER sepiolite has a formula $\left[\mathrm{Si}_{11.99} \mathrm{Al}_{0.01} \mathrm{O}_{30} \mathrm{Mg}_{7.92} \mathrm{Al}_{0.03}\right.$ $\left.\mathrm{Fe}_{0.01}^{3+}(\mathrm{OH})_{4}\left(\mathrm{OH}_{2}\right)_{4} \cdot 8 \mathrm{H}_{2} \mathrm{O}\right]$ closer to the theoretical one.

\section{Morphology}

Sepiolites can be classified from the point of view of the morphology into two groups, macroscopic and clay-sepiolite. They roughly correspond to different types of formation conditions. SEM and TEM images can reveal detailed fiber morphology. All samples of sepiolite have been studied by SEM and most of them by TEM. From these images (some of them shown in Fig. 2), several parameters were extracted:

- The length of the fibers (Figs. 2a-2d) ranges from tenths of micrometers to centimeters. Although there is a continuous variation of fiber length with no apparent gap, sepiolites can be classified in four groups according to this parameter: (1) macroscopic sepiolite, with fibers longer than a centimeter (FIN, HEN, NEI, NOR, and XIX), (2) long fiber sepiolite with lengths longer than $10 \mu \mathrm{m}$ (MON, SAN, TPO, VIC, and YUN), (3) intermediate fiber sepiolite, with lengths between 1 and $10 \mu \mathrm{m}$ (SOM, GRA, and MER), and (4) short fiber sepiolite with length less than 1

TABLE 2. Results of compositional analysis (AEM) for the different sepiolites (García-Romero and Suárez 2010)

\begin{tabular}{|c|c|c|c|c|c|c|c|c|c|c|c|c|}
\hline & $\mathrm{Si}$ & $\mathrm{Al}^{\mathrm{IV}}$ & $\Sigma \tau$ & $\mathrm{Al}^{\mathrm{VI}}$ & $\mathrm{Fe}^{3+}$ & $\mathrm{Mg}$ & $\mathrm{Ti}$ & $\Sigma 0$ & $\mathrm{Ca}$ & $\mathrm{K}$ & $\mathrm{Na}$ & $\mathrm{N}$ \\
\hline BAT & $11.81(22)$ & $0.19(20)$ & $12.00(4)$ & $0.68(29)$ & $0.28(16)$ & $6.10(69)$ & $0.13(12)$ & $7.19(36)$ & $0.18(17)$ & $0.12(13)$ & $0.04(11)$ & 19 \\
\hline BOS & $11.77(4)$ & $0.23(36)$ & $12.00(6)$ & $0.31(17)$ & $0.28(21)$ & $6.71(59)$ & & $7.30(37)$ & $0.29(28)$ & $0.31(38)$ & & 14 \\
\hline FIN & $11.72(27)$ & $0.28(25)$ & $12.00(4)$ & $0.12(16)$ & $0.61(16)$ & $6.66(45)$ & & $7.46(26)$ & $0.25(18)$ & $0.17(20)$ & $0.05(9)$ & 14 \\
\hline GRA & $12.00(9)$ & & $12.00(6)$ & $0.09(7)$ & $0.05(6)$ & $7.58(22)$ & & $7.72(16)$ & $0.07(6)$ & $0.02(2)$ & $0.15(15)$ & 13 \\
\hline HEN & $11.95(10)$ & $0.05(7)$ & $12.00(4)$ & $0.11(12)$ & $0.07(6)$ & $7.61(25)$ & & $7.79(15)$ & $0.06(7)$ & $0.04(6)$ & $0.07(15)$ & 33 \\
\hline LIE & $12.00(14)$ & & $12.00(5)$ & $1.18(40)$ & $0.32(18)$ & $5.52(74)$ & & $7.02(30)$ & $0.06(2)$ & $0.04(11)$ & $0.13(4)$ & 15 \\
\hline MAR & $11.80(29)$ & $0.20(24)$ & $12.00(6)$ & $0.45(21)$ & $0.28(18)$ & $6.82(40)$ & $0.02(4)$ & $7.57(22)$ & $0.05(7)$ & $0.06(7)$ & $0.01(3)$ & 30 \\
\hline MER & 11.99(6) & $0.01(4)$ & $12.00(30)$ & $0.03(4)$ & $0.01(1)$ & $7.92(10)$ & & 7.96(6) & $0.01(1)$ & $0.01(2)$ & & 6 \\
\hline MON & 11.97(19) & $0.03(14)$ & $12.00(6)$ & $0.22(16)$ & $0.21(10)$ & $7.21(30)$ & & $7.64(16)$ & $0.07(4)$ & $0.04(5)$ & & 23 \\
\hline NAM & $11.97(16)$ & $0.03(9)$ & $12.00(10)$ & $0.16(10)$ & $0.08(12)$ & $7.45(35)$ & & $7.69(23)$ & $0.10(10)$ & $0.04(6)$ & & 20 \\
\hline NEI & $11.73(47)$ & $0.27(36)$ & $12.00(6)$ & $0.17(22)$ & $0.21(25)$ & $7.20(58)$ & & $7.57(27)$ & $0.18(25)$ & $0.16(21)$ & $0.01(3)$ & 25 \\
\hline NEV & $11.68(35)$ & $0.32(29)$ & $12.00(9)$ & $0.17(15)$ & $0.19(4)$ & $7.40(36)$ & & $7.76(20)$ & $0.16(24)$ & $0.12(10)$ & $0.04(9)$ & 31 \\
\hline NOR & $11.95(15)$ & $0.05(11)$ & $12.00(7)$ & $0.14(22)$ & $0.05(6)$ & $7.48(37)$ & $0.01(4)$ & $7.68(20)$ & $0.06(10)$ & $0.10(25)$ & $0.06(12)$ & 26 \\
\hline SAN & $12.00(8)$ & & $12.00(5)$ & $0.02(3)$ & $0.06(4)$ & $7.69(19)$ & & $7.77(16)$ & $0.06(3)$ & $0.01(2)$ & $0.09(14)$ & 12 \\
\hline SOM & $11.92(17)$ & $0.08(15)$ & $12.00(5)$ & $0.13(9)$ & $0.07(8)$ & $7.61(18)$ & & $7.81(12)$ & $0.05(7)$ & $0.06(9)$ & $0.03(6)$ & 22 \\
\hline TPO & $12.00(8)$ & & $12.00(5)$ & $0.04(6)$ & $0.05(4)$ & 7.76(17) & & $7.85(13)$ & $0.04(5)$ & & $0.04(10)$ & 11 \\
\hline VAL & $11.84(29)$ & $0.16(23)$ & $12.00(5)$ & $0.25(15)$ & $0.06(10)$ & $7.35(36)$ & $0.03(6)$ & $7.69(20)$ & $0.05(11)$ & $0.08(13)$ & $0.06(18)$ & 17 \\
\hline VIC & $11.77(29)$ & $0.23(27)$ & $12.00(2)$ & $0.27(18)$ & $0.23(29)$ & $7.22(46)$ & & $7.72(17)$ & $0.10(13)$ & $0.06(8)$ & $0.01(6)$ & 20 \\
\hline XIX & $12.00(6)$ & & $12.00(6)$ & $0.10(2)$ & $0.12(6)$ & $7.53(14)$ & & $7.66(14)$ & $0.02(3)$ & & $0.07(16)$ & 6 \\
\hline YUN & $12.00(5)$ & & $12.00(4)$ & $0.27(4)$ & $0.03(2)$ & $7.45(9)$ & & $7.69(8)$ & $0.02(1)$ & $0.01(1)$ & $0.03(5)$ & 20 \\
\hline
\end{tabular}

Note: Last column $(\mathrm{N})$ indicates the number of measurements used for calculating the average and standard deviation. 

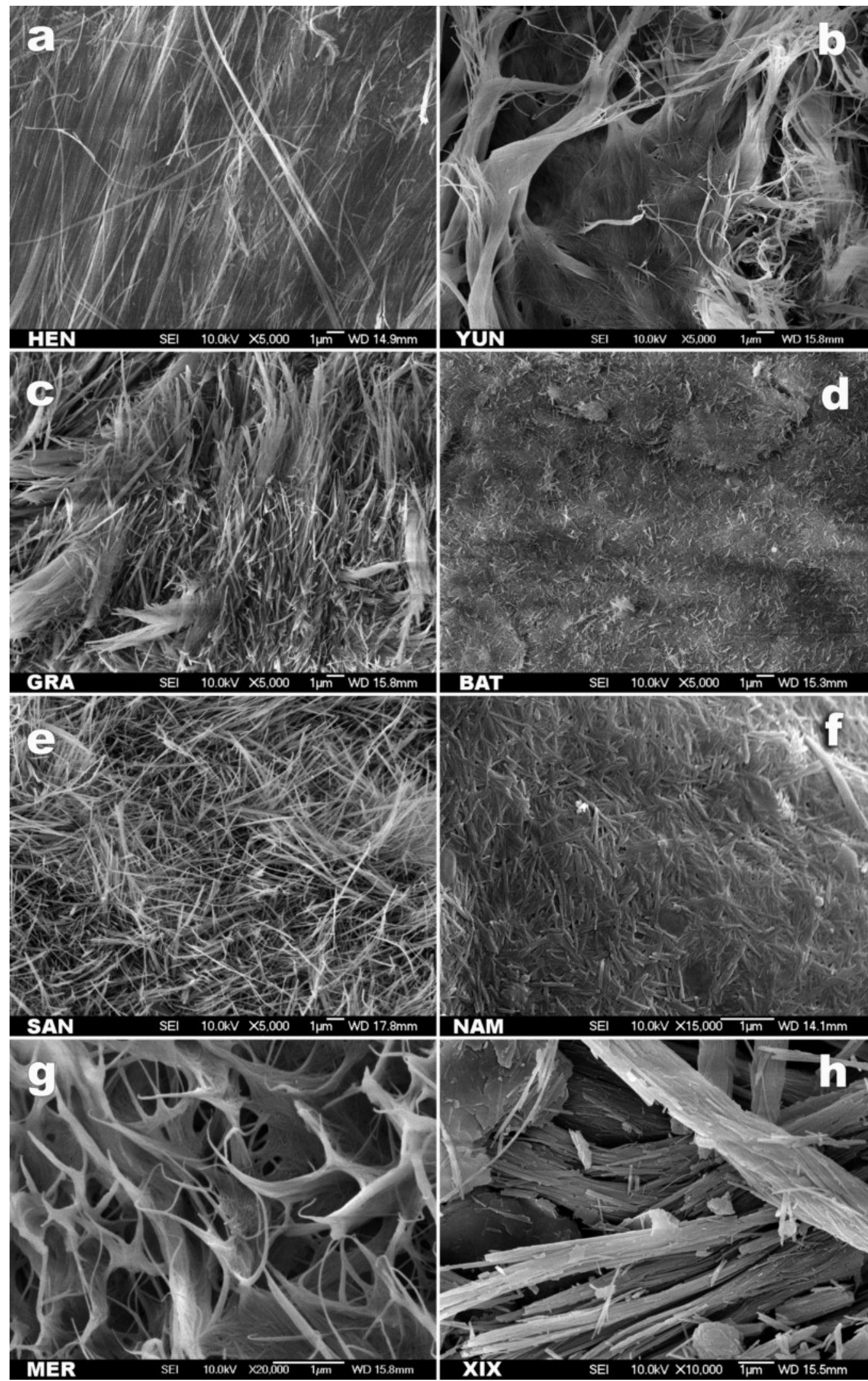

FIGURE 2. SEM images of different sepiolites, following different classifications: (1) fiber length classification: (a) macroscopic, (b) long, (c) intermediate, (d) short; (2) aggregation classification: (e) open porosity, (f) closed porosity; (3) geometry classification: (g) curled. The image $\mathbf{h}$ illustrates the packing of the individual fibers into wider bunch of fibers. Note that a-e images have the same magnification $(\times 5000)$ to better compare the fiber shape, and $\mathbf{f}-\mathbf{h}$ are higher magnified to emphasize smaller details. 
$\mu \mathrm{m}$ (BAT, MAR, NAM, and NEV). Figures $2 \mathrm{a}$ to $2 \mathrm{~d}$ show some images for some sepiolites following this classification.

- The aggregation (or bundling) of the fibers (Figs. 2e-2f for an example) either presents open porosity (fibers look as isolated sticks, like SAN and SEI) or closed porosity (fibers forming a dense mesh, as NAM or NEV).

- The geometry of the fibers can be related to their curvature, rigidity, and aspect ratio (Fig. $2 \mathrm{~g}$ ). One can easily distinguish curled (like MER, Fig. 2g) or straight (most of the others) fibers.

- The width of the fibers is variable. It can be recognized that most fibers are composed of smaller fibers (down to a few tens of nanometers) forming bundles, which in turn are formed by different fibers of different width (Fig. 2h).

The same sepiolite sample may be inhomogeneous in the sense that different parts of the same sample may be classified

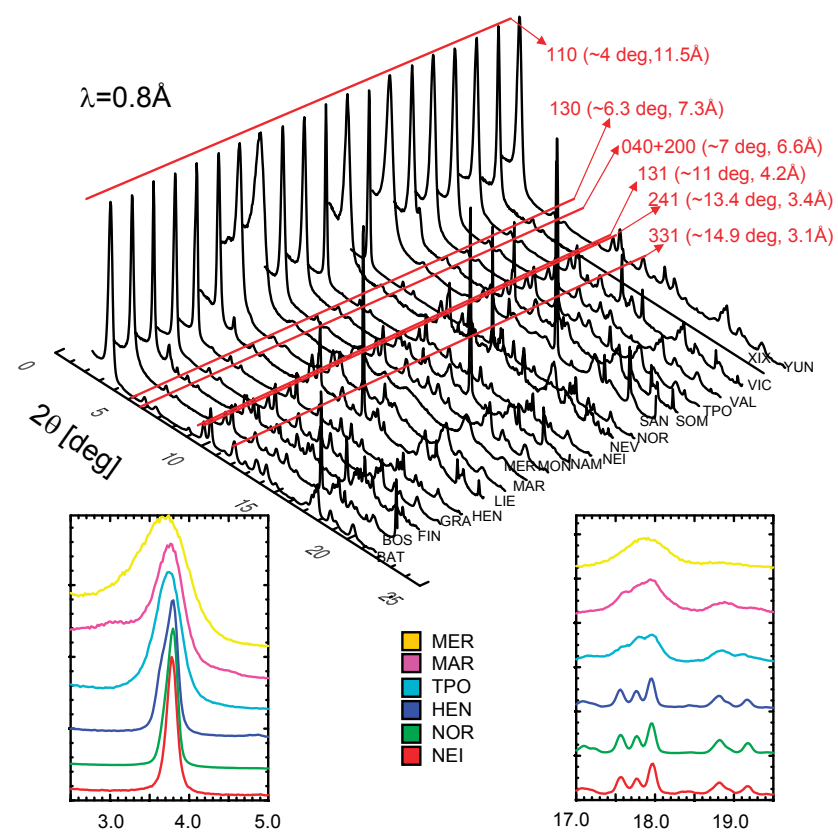

FIGURE 3. Powder diffraction patterns for the sepiolite samples listed in Table 1. Each diffraction pattern is normalized to the (110) peak. The insets show in detail the (110) peak and the 17.0-19.5 degree zone for some of the most and less crystalline sepiolites.

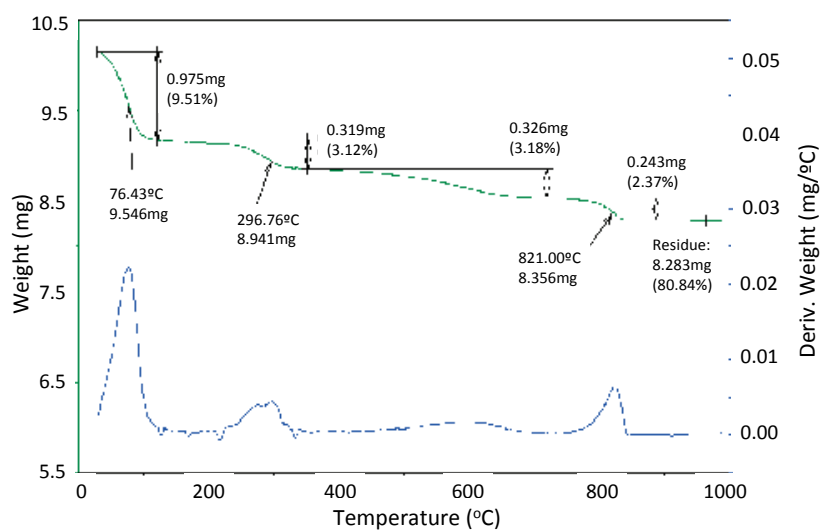

FIGURE 4. Thermogravimetry curve for the NOR sample. The first step corresponds to the loss of hygroscopic and zeolitic water. into different groups. We have not observed marked differences in the composition, neither in the octahedral content nor in the tetrahedral or octahedral substitutions between the macroscopic and clay-sepiolite groups.

\section{Powder diffraction}

Figure 3 shows the X-ray diffraction patterns taken from all samples. We observed some clear differences in peak position, peak width, and relative intensity, suggesting variability in cell parameters, crystallinity, and composition, respectively.

Because of the large overlapping of reflections in the sepiolite diffraction pattern, only a few peaks can be analyzed to directly obtain information on the $d$-spacing and reflection width. The peaks that form a non-overlapping reflection are $(110)\left(\sim 3.95^{\circ}\right)$, (130) $\left(\sim 6.3^{\circ}\right),(131)\left(\sim 11^{\circ}\right),(241)\left(\sim 13.4^{\circ}\right)$, and $(331)\left(\sim 14.9^{\circ}\right)$. We used the two first reflections [(110) and (130)] to extract the peak width and $d$-spacing. The (110) peak has been fitted with a pseudo-Voigt function to obtain peak position and width. However, because the (110) reflection appears at a very low $2 \theta$, there is an important asymmetry induced by both the instrumental function and the sample itself (Finger et al. 1994). Thus, it is crucial to include this effect in the fit, because the asymmetry makes that the real position of the peak appears at higher $2 \theta$ than the apparent peak position (the position that one would select by simply selecting the top of the peak). The possible asymmetry due to Lorentz polarization factor and possibly the angular dependence of the structure factor contribute to a smooth varying background (Janeba et al. 1998). This is included in our case in the subtracted background, calculated using a multi-strip algorithm. The peak width is related to crystallinity. Table 3 shows the full-width at half maximum (FWHM) of the (110) reflection for all sepiolites studied, evidencing that the most crystalline samples (macroscopic sepiolites) have smaller width (see inset in Fig. 3). It also shows an important change in the peak position that could, in principle, be attributed to modifications in the cell dimensions originated by compositional variations caused by isomorphic substitutions or different crystallinity. However, the peak position of the (110) reflection (Table 3 ) is not correlated with morphology and crystallinity of the samples. The (130) peak is also fitted with a pseudo-Voigt function using the same asymmetry parameter obtained from the fit of the (110) peak. Consistently, it can be observed that the width of the (130) peak decreases with crystallinity at the same ratio as the width of the (110) peak. Table 3 also displays the cell parameters $a$ and $b$ calculated from the two reflections.

We have searched for correlations among the structural parameters [the positions of the (110) and (131) reflections, their widths, the asymmetry factor, and the resulting $a$ and $b$ ] and compositional values (Table 2), to associate the cell parameter $a$ with the Mg content, as it was found for palygorskite (Stathopoulou et al. 2011; Suárez et al. 2007). One can hypothesize that there is a relationship between crystallochemical features and the cell parameters (position of the peaks). The (110) position is influenced mainly by the total content of the octahedral sheet, with a correlation coefficient c.c. $=0.614$, while the $(130)$ peak has an inverse relation to the sum of $\mathrm{Al}$ and $\mathrm{Fe}$ contents (c.c. $=$ $-0.661)$. This implies that $a$ and $b$ can also be related to these crystallochemical parameters, $a$ being mostly influenced by the 
TABLE 3. Morphological classification of sepiolites looking at the length of the fibers and parameters from X-ray powder diffraction: $d$-spacing, FWHM (in deg) of the 110 and 131 peaks, the asymmetry parameter (see text), and the resulting cell parameters $a$ and $b$

\begin{tabular}{|c|c|c|c|c|c|c|c|c|}
\hline & Length & $110 d(\AA)$ & $130 d(\AA)$ & $110 \mathrm{FWHM}$ & $130 \mathrm{FWHM}$ & Asym (D_L) & $a(\AA)$ & $b(\AA)$ \\
\hline BAT & short & $11.898(8)$ & $7.444(2)$ & $0.278(2)$ & $0.219(4)$ & $0.038(2)$ & $13.255(12)$ & $26.993(16)$ \\
\hline BOS & $p$ & $11.940(2)$ & $7.453(2)$ & $0.215(2)$ & $0.189(4)$ & $0.028(12)$ & $13.315(3)$ & $26.980(11)$ \\
\hline FIN & macroscopic & $12.032(1)$ & $7.482(2)$ & $0.139(2)$ & $0.150(7)$ & $0.021(17)$ & $13.438(2)$ & $27.021(11)$ \\
\hline GRA & intermediate & $11.988(11)$ & $7.464(2)$ & $0.227(2)$ & $0.192(4)$ & $0.030(2)$ & $13.382(17)$ & 26.977(19) \\
\hline HEN & macroscopic & $11.986(1)$ & $7.473(2)$ & $0.140(1)$ & $0.125(5)$ & $0.033(6)$ & $13.372(2)$ & $27.034(10)$ \\
\hline LIE & $\mathrm{p}$ & $11.858(3)$ & $7.400(3)$ & $0.235(1)$ & $0.241(13)$ & $0.026(12)$ & $13.224(6)$ & $26.788(18)$ \\
\hline MAR & short & $11.973(12)$ & $7.418(0)$ & $0.342(2)$ & $0.264(0)$ & $0.051(7)$ & $13.392(18)$ & $26.731(16)$ \\
\hline MER & intermediate & $12.173(4)$ & $7.538(3)$ & $0.607(2)$ & $0.383(10)$ & $0.042(12)$ & $13.618(7)$ & $27.154(20)$ \\
\hline MON & long & $11.993(2)$ & $7.470(2)$ & $0.244(2)$ & $0.244(5)$ & $0.030(12)$ & $13.385(3)$ & $27.010(11)$ \\
\hline NAM & short & $11.970(8)$ & $7.462(3)$ & $0.263(2)$ & $0.206(11)$ & $0.036(1)$ & $13.356(13)$ & 26.991(19) \\
\hline NEI & macroscopic & $12.022(2)$ & $7.472(2)$ & $0.131(1)$ & $0.114(6)$ & $0.024(8)$ & $13.429(3)$ & 26.979(9) \\
\hline NEV & short & $11.900(2)$ & $7.429(3)$ & $0.383(1)$ & $0.437(7)$ & $0.039(9)$ & $13.270(4)$ & $26.900(16)$ \\
\hline NOR & macroscopic & $12.026(1)$ & $7.479(1)$ & $0.134(1)$ & $0.121(3)$ & $0.026(6)$ & $13.430(2)$ & $27.012(8)$ \\
\hline SAN & long & $12.046(2)$ & $7.509(4)$ & $0.473(1)$ & $0.362(12)$ & $0.044(8)$ & $13.440(4)$ & $27.164(21)$ \\
\hline SOM & intermediate & $11.927(2)$ & $7.474(3)$ & $0.291(2)$ & $0.279(9)$ & $0.034(12)$ & $13.279(4)$ & $27.124(20)$ \\
\hline TPO & long & $12.020(10)$ & $7.487(2)$ & $0.338(2)$ & $0.275(7)$ & $0.039(1)$ & $13.415(15)$ & $27.068(20)$ \\
\hline VAL & long & $12.015(9)$ & $7.468(2)$ & $0.292(2)$ & $0.217(7)$ & $0.037(1)$ & $13.420(14)$ & $26.967(18)$ \\
\hline VIC & long & $11.959(7)$ & $7.438(2)$ & $0.278(1)$ & $0.210(7)$ & $0.044(12)$ & $13.356(11)$ & $26.864(17)$ \\
\hline XIX & macroscopic & $11.917(6)$ & $7.445(2)$ & $0.205(2)$ & $0.191(13)$ & $0.035(1)$ & $13.284(10)$ & $26.969(15)$ \\
\hline YUN & long & $12.024(8)$ & $7.541(2)$ & $0.309(2)$ & $0.310(5)$ & $0.039(0)$ & $13.383(12)$ & $27.383(18)$ \\
\hline
\end{tabular}

Note: $\mathrm{p}=$ samples supplied by companies in the form of powder.

trioctahedral character of the sample (sum of octahedral cations vs. $a$, c.c. $=0.574)$ and by the content in $\mathrm{Mg}+\mathrm{Fe}^{3+}($ c.c. $=0.570)$. This behavior was also found in palygorskite, were an expansion in $a$ was explained by the fact that cations with larger ionic radii predominate over smaller cations (Suárez et al. 2007). The cell parameter $b$ is related to the sum of $\mathrm{Al}$ plus $\mathrm{Fe}^{3+}$ contents (c.c. $=$ $-0.555)$, therefore the samples richest in these elements present the smaller expansion along [010].

\section{Rietveld refinement}

Three sepiolites have been chosen to perform Rietveld refinement: NOR, GRA, and BAT. The first two samples present high purity and crystallinity. The BAT sepiolite is the most aluminic in the list. They were measured at two temperatures: $25^{\circ} \mathrm{C}$ (room temperature) and $225^{\circ} \mathrm{C}$. The high temperature has been chosen according to the thermogravimetry curve for the NOR sample (Fig. 4), which has been normalized using compositional data for NOR from Table 2. The temperature of $225^{\circ} \mathrm{C}$ is high enough to allow complete dehydration of the hygroscopic plus zeolitic $\mathrm{H}_{2} \mathrm{O}$, but not enough to start dehydration of coordinated $\mathrm{OH}_{2}$, producing the folding of the structure (Frost and Ding 2003; Serna et al. 1975).

We started with the sepiolite model proposed by (Brauner and Preisinger 1956). Within this model, sepiolite is orthorhombic, with the space group Pncn and approximate cell parameters $a=$ $13.4, b=2 a, c=5.28 \AA$. The atomic coordinates were obtained from the ICSD database (PDF $=26-1226)$. In the refinement, the occupation number of the different atomic positions should correspond to those given by the structural formula without zeolitic $\mathrm{H}_{2} \mathrm{O}$ [BAT: $\left(\mathrm{Si}_{11.81} \mathrm{Al}_{0.19}\right) \mathrm{O}_{30}\left(\mathrm{Al}_{0.68} \mathrm{Fe}_{0.28}^{3+} \mathrm{Mg}_{6.1} \mathrm{Ti}_{0.13}\right)(\mathrm{OH})_{4}\left(\mathrm{OH}_{2}\right)_{4}$, NOR: $\left(\mathrm{Si}_{11.95} \mathrm{Al}_{0.05}\right) \mathrm{O}_{30}\left(\mathrm{Al}_{0.14} \mathrm{Fe}_{0.05}^{3+} \mathrm{Mg}_{7.48} \mathrm{Ti}_{0.01}\right)(\mathrm{OH})_{4}\left(\mathrm{OH}_{2}\right)_{4}$, and GRA: $\left.\mathrm{Si}_{12.00} \mathrm{O}_{30}\left(\mathrm{Al}_{0.09} \mathrm{Fe}_{0.05}^{3+} \mathrm{Mg}_{7.58}\right)(\mathrm{OH})_{4}\left(\mathrm{OH}_{2}\right)_{4}\right]$. However, since these sepiolites present a negligible tetrahedral substitution, it has been considered that all tretrahedra are fully filled with Si. Also, the $\mathrm{Al}$ and Fe octahedral substitution is very small for NOR and GRA. The Al contribution can be added to the $\mathrm{Mg}$ contribution, a reasonable approximation considering that $\mathrm{Mg}$ and $\mathrm{Al}$ have contiguous atomic numbers, resulting in a similar scattering power to the X-rays. Therefore, the Mg occupancy was fixed to that of the whole octahedral contribution. The hydrogen atoms are neglected due to their small scattering power. The refinement is started using the dehydrated sepiolite diffraction patterns, which permits to reduce the number of adjustable parameters in a first step, avoiding the inclusion of zeolitic $\mathrm{H}_{2} \mathrm{O}$, which shows high mobility and low-scattering power to the $\mathrm{X}$-rays.

The diffraction patterns for the three dehydrated sepiolites at $225^{\circ} \mathrm{C}$ (Fig. 5, Tables 4 and 5, CIF files are deposited ${ }^{1}$ ) show a reasonable agreement with the same crystallographic model. There are however some peaks that are not reproduced by the model and are due to other phases, like those about $2 \theta=16.2^{\circ}$. The sepiolites analyzed, although selected by their high purity, are natural materials thus not free from other crystalline phases in small quantity (less than 1\%). In the refinements, it has been necessary to remove a background that contains several wide oscillations, indicating the presence of amorphous phases (in addition to the glass capillary). The NOR and GRA samples show better fits than the BAT sample. The latter corresponds to the sepiolite with higher $\mathrm{Al}$ content. $\mathrm{As} \mathrm{Al}$ and $\mathrm{Mg}$ have similar atomic numbers ( $Z=13$ and $Z=12$, respectively), they present very similar scattering power to the X-rays, thus a random replacement of $\mathrm{Mg}$ by $\mathrm{Al}$ should not much affect the intensities in the diffraction pattern. Therefore, the differences of the experimental intensities with respect to the model in the BAT sepiolite indicate that $\mathrm{Al}$ does not replace $\mathrm{Mg}$ uniformly, but instead forms clusters or zones where the octahedral sheets contain high-Al concentrations probably with a different structure. In fact, the compositional continuity when going from sepiolite to palygorskite (Suárez et al. 2010) is also reflected in the structure: Stathopoulou et al. (2011) showed the mixed dioctahedraltrioctahedral character of Mg-rich palygorskites, suggesting a

\footnotetext{
${ }^{1}$ Deposit item AM-11-053, CIF. Deposit items are available two ways: For a pape copy contact the Business Office of the Mineralogical Society of America (see inside front cover of recent issue) for price information. For an electronic copy visit the MSA web site at http://www.minsocam.org, go to the American Mineralogist Contents, find the table of contents for the specific volume/issue wanted, and then click on the deposit link there.
} 
TABLE 4. Parameters from Rietveld refinement for the three sepiolites analyzed (BAT, GRA, and NOR) at two temperatures $\left(25\right.$ and $\left.225^{\circ} \mathrm{C}\right)$

\begin{tabular}{|c|c|c|c|c|c|c|c|c|}
\hline & BAT225 & GRA225 & NOR225 & BAT25 & GRA25 & NOR25 & POST & B\&P \\
\hline \multicolumn{9}{|l|}{ Unit cell } \\
\hline$a$ & $13.2608(15)$ & $13.3317(6)$ & $13.3765(2)$ & $13.3067(9)$ & $13.3638(7)$ & $13.4074(2)$ & 13.4051 & 13.4000 \\
\hline$b$ & $27.0559(15)$ & $27.0493(8)$ & $27.0850(3)$ & $26.9720(11)$ & $27.0034(10)$ & $27.0244(4)$ & 27.0161 & 26.8000 \\
\hline c & $5.2671(2)$ & $5.2694(1)$ & $5.2757(1)$ & $5.2664(2)$ & $5.2716(2)$ & $5.2767(1)$ & 5.2750 & 5.2800 \\
\hline v & $1889.76(25)$ & $1900.23(11)$ & $1911.39(4)$ & $1890.17(17)$ & $1902.33(13)$ & $1911.89(5)$ & 1910.36 & 1896.15 \\
\hline Number of data points & 3895 & 3895 & 3895 & 3895 & 3895 & 3895 & 1871 & \\
\hline Number of reflections & 3937 & 4326 & 4014 & 4027 & 4178 & 4012 & 1058 & \\
\hline $\operatorname{Max} d(\AA \AA)$ & 22.34 & 22.34 & 22.34 & 22.33 & 22.33 & 22.34 & 9.10 & \\
\hline $\operatorname{Min} d(\AA)$ & 0.63 & 0.61 & 0.63 & 0.63 & 0.62 & 0.63 & 0.99 & \\
\hline RF-factor (\%) & 3.32 & 7.99 & 6.63 & 5.99 & 8.25 & 4.74 & 5.50 & \\
\hline Bragg R-factor (\%) & 3.18 & 5.73 & 4.56 & 6.58 & 8.23 & 6.57 & 0.00 & \\
\hline$R_{\mathrm{p}} \%$ & 12.70 & 10.30 & 6.99 & 11.50 & 14.40 & 9.76 & 0.00 & \\
\hline$R_{\mathrm{wp}} \%$ & 17.20 & 10.50 & 7.73 & 13.30 & 15.90 & 10.50 & 2.10 & \\
\hline$R_{\mathrm{e}} \%$ & 1.33 & 2.52 & 1.60 & 1.46 & 1.91 & 1.89 & 0.00 & \\
\hline$x^{2}$ & 166.500 & 17.490 & 23.400 & 82.180 & 69.020 & 30.840 & 0.125 & \\
\hline
\end{tabular}

sepiolite-palygorskite polysomatism. Following these ideas, the excess of Al in BAT should be accompanied by dioctahedral clusters of palygorskite, where the ration $\mathrm{Al} / \mathrm{Mg}$ is one and the ribbons are narrower in $b$, (3 octahedra for palygorskite instead of 5 for sepiolite). These clusters appear as interstratifications that are small enough to be resolved as palygorskite in the diffraction patterns, but strong enough to avoid a good refinement with a one-structure model, as attempted here. Work is in progress to apply disordered models (Viani et al. 2002) to simulate and fit the effect of the interstratifications in the X-ray powder pattern.

The cell parameter values previously obtained from the fits of the (110) and (130) reflections (Table 3) are in agreement (better than $0.4 \%$ ) with the more precise ones obtained by Rietveld, thus confirming the necessary incorporation of the peak asymmetry in the fit. There are important discrepancies in the cell parameter $a$ among the three sepiolites, small differences in $b$, and almost no distinction in $c$ (to which X-ray diffraction is less sensitive, because the fibers tend to orientate along the $c$ axis direction). These differences may be related to the chemical composition as discussed before, but no correlation has been found so far.

In Figure 4, the thermogravimetry curve for the NOR sample (Fig. 4) shows a loss of $9.52 \%$ of weight, which correspond to the loss of roughly six zeolitic $\mathrm{H}_{2} \mathrm{O}$ molecules $(8.77 \%$ ) plus a small amount of hygroscopic water instead of the eight $\mathrm{H}_{2} \mathrm{O}$ molecules from the ideal formula. There are two different models in literature for positioning the zeolitic $\mathrm{H}_{2} \mathrm{O}$ in the unit cell, one with three different positions in the asymmetric unit thus leading to a total of eight $\mathrm{H}_{2} \mathrm{O}$ molecules when the positions are fully occupied (Brauner and Preisinger 1956) (B\&P) and another with four positions (Post et al. 2007) (7.24 $\mathrm{H}_{2} \mathrm{O}$ molecules when considering the refined occupation). To differentiate between these models, we have used global-optimization algorithms to positioning zeolitic $\mathrm{H}_{2} \mathrm{O}$ in the NOR sepiolite framework by means of the FOX software (Favre-Nicolin and Cerny 2002). Four molecules of $\mathrm{H}_{2} \mathrm{O}$ were arbitrarily placed into the dehydrated sepiolite asymmetric unit and allowed to freely accommodate within the cell. The $\mathrm{H}_{2} \mathrm{O}$ molecules were allowed to migrate in direct space to find the positions that best fits the experimental data. The best results were obtained for only two positions in the asymmetric unit $[(0.984,0.328,0.315)$ and $(0.443,0.931,0.493)]$ with occupations of 0.73 and 1 , respectively, thus totaling 6.9 molecules of zeolitic $\mathrm{H}_{2} \mathrm{O}$ per unit formula (half unit cell). These positions are not far from those of B\&P, therefore our initial configuration for

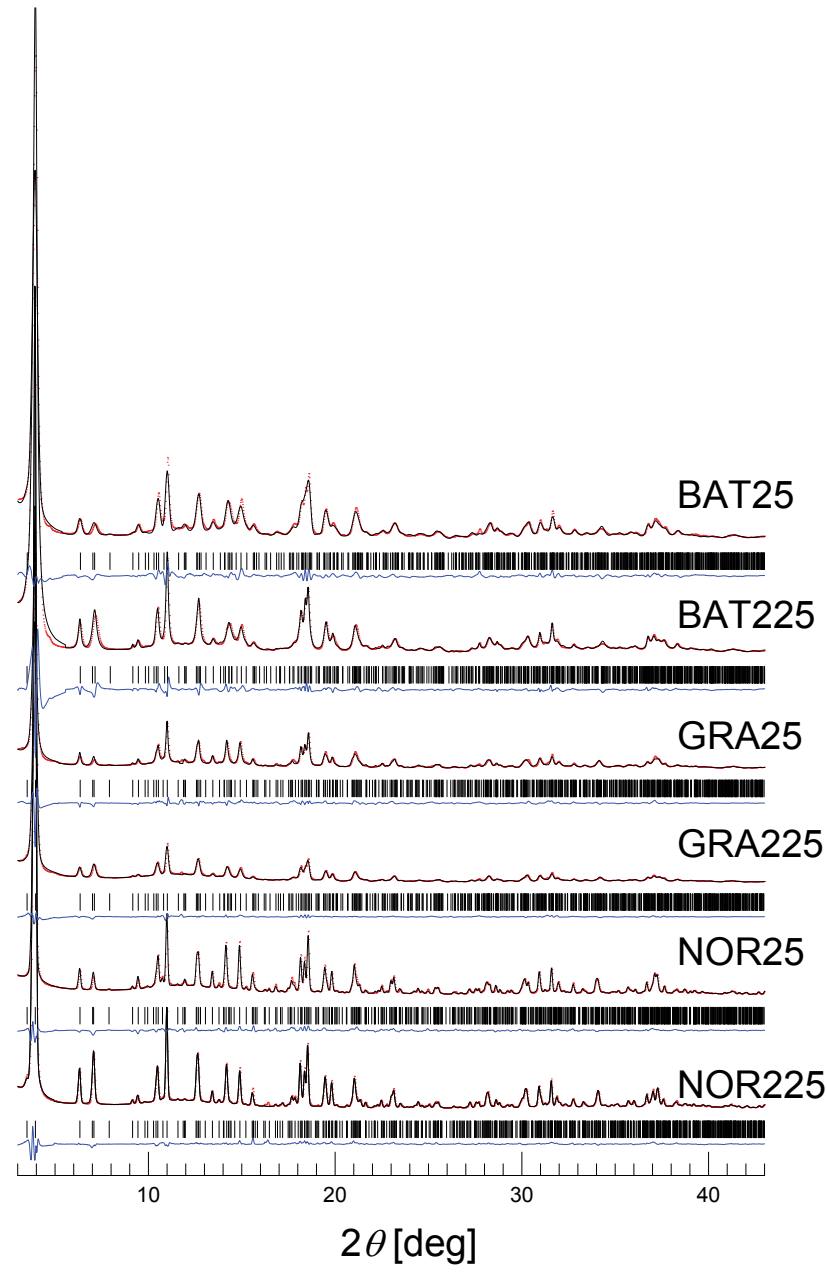

FIGURE 5. Rietveld refinements for NOR, GRA, and BAT at 25 and $225^{\circ} \mathrm{C}$. The experimental (dotted line) and calculated (continuous line) diffraction patterns are represented together with their differences and Bragg positions.

starting the refinement includes the $\mathrm{B} \& \mathrm{P}$ zeolitic $\mathrm{H}_{2} \mathrm{O}$ positions in the mainframe of sepiolite obtained from the refinement of hydrated sepiolite.

As in the case of dehydrated sepiolite, acceptable fits are obtained for NOR and GRA while less good ones were found for 
TABLE 5. Atomic position for NOR, GRA, and BAT at $25^{\circ} \mathrm{C}$ (hydrated) and $225^{\circ} \mathrm{C}$ (dehydrated) sepiolites from Rietveld refinement

\begin{tabular}{|c|c|c|c|c|c|c|c|c|c|c|c|c|c|}
\hline & & & BAT225 & & & & & BAT25 & & & & & \\
\hline & $x$ & $y$ & z & $B_{\text {iso }}$ & Occ & $x$ & $y$ & z & $B_{\text {iso }}$ & Occ & & & \\
\hline SI1 & $0.1917(9)$ & $0.0296(7)$ & $0.583(3)$ & $0.45(5)$ & $1.000(0)$ & $0.1970(6)$ & $0.0265(4)$ & $0.580(2)$ & $1.19(5)$ & $1.000(0)$ & & & \\
\hline $\mathrm{SI} 2$ & $0.2061(12)$ & $0.1421(5)$ & $0.564(3)$ & $0.45(5)$ & $1.000(0)$ & $0.2146(8)$ & $0.1399(3)$ & $0.570(2)$ & $1.19(5)$ & $1.000(0)$ & & & \\
\hline SI3 & $0.2131(11)$ & $0.1943(5)$ & $0.073(3)$ & $0.45(5)$ & $1.000(0)$ & $0.2073(8)$ & $0.1940(3)$ & $0.066(2)$ & $1.19(5)$ & $1.000(0)$ & & & \\
\hline Mg1 & $0.0000(0)$ & $0.0228(13)$ & $0.250(0)$ & $1.33(21)$ & $0.449(0)$ & $0.0000(0)$ & $0.0274(8)$ & $0.250(0)$ & $1.62(14)$ & $0.449(0)$ & & & \\
\hline Mg2 & $0.0000(0)$ & $0.0903(13)$ & $0.750(0)$ & $1.33(21)$ & $0.449(0)$ & $0.0000(0)$ & $0.0920(7)$ & $0.750(0)$ & $1.62(14)$ & $0.449(0)$ & & & \\
\hline Mg3 & $0.0000(0)$ & $0.1482(12)$ & $0.250(0)$ & $1.33(21)$ & $0.449(0)$ & $0.0000(0)$ & $0.1463(7)$ & $0.250(0)$ & $1.62(14)$ & $0.449(0)$ & & & \\
\hline Mg4 & $0.0000(0)$ & $0.2023(11)$ & $0.750(0)$ & $1.33(21)$ & $0.449(0)$ & $0.0000(0)$ & $0.2031(6)$ & $0.750(0)$ & $1.62(14)$ & $0.449(0)$ & & & \\
\hline 09 & $0.2500(0)$ & $0.2500(0)$ & $0.103(9)$ & $1.11(16)$ & $0.500(0)$ & $0.2500(0)$ & $0.2500(0)$ & $0.088(6)$ & $1.19(10)$ & $0.500(0)$ & & & \\
\hline 01 & $0.0915(23)$ & $0.0262(16)$ & $0.576(8)$ & $1.11(16)$ & $1.000(0)$ & $0.0675(12)$ & $0.0203(7)$ & $0.578(4)$ & $1.19(10)$ & $1.000(0)$ & & & \\
\hline $\mathrm{O} 3$ & $0.0759(24)$ & $0.1490(12)$ & $0.560(7)$ & $1.11(16)$ & $1.000(0)$ & $0.0599(13)$ & $0.1378(6)$ & $0.571(4)$ & $1.19(10)$ & $1.000(0)$ & & & \\
\hline O4 & $0.1102(23)$ & $0.1968(11)$ & $0.078(8)$ & $1.11(16)$ & $1.000(0)$ & $0.0959(12)$ & $0.1917(7)$ & $0.024(4)$ & $1.19(10)$ & $1.000(0)$ & & & \\
\hline $\mathrm{O} 5$ & $0.2627(25)$ & $0.0053(12)$ & $0.344(8)$ & $1.11(16)$ & $1.000(0)$ & $0.2531(14)$ & $-0.0010(6)$ & $0.345(4)$ & $1.19(10)$ & $1.000(0)$ & & & \\
\hline $\mathrm{O} 6$ & $0.2363(23)$ & $0.0933(12)$ & $0.582(6)$ & $1.11(16)$ & $1.000(0)$ & $0.2555(14)$ & $0.0751(6)$ & $0.591(4)$ & $1.19(10)$ & $1.000(0)$ & & & \\
\hline O7 & $0.2655(25)$ & $0.1648(12)$ & $0.326(7)$ & $1.11(16)$ & $1.000(0)$ & $0.2640(15)$ & $0.1619(6)$ & $0.271(3)$ & $1.19(10)$ & $1.000(0)$ & & & \\
\hline $\mathrm{O} 8$ & $0.2676(26)$ & $0.1672(14)$ & $0.787(6)$ & $1.11(16)$ & $1.000(0)$ & $0.3231(13)$ & $0.1619(6)$ & $0.818(3)$ & $1.19(10)$ & $1.000(0)$ & & & \\
\hline $\mathrm{O} 2-\mathrm{OH}$ & $0.0809(20)$ & $0.0863(16)$ & $0.070(6)$ & $1.11(16)$ & $1.000(0)$ & $0.0942(11)$ & $0.0847(7)$ & $0.080(3)$ & $1.19(10)$ & $1.000(0)$ & & & \\
\hline O10-CW & $0.0607(21)$ & $0.2520(10)$ & $0.598(6)$ & $1.11(16)$ & $1.000(0)$ & $0.0745(13)$ & $0.2617(6)$ & $0.538(3)$ & $1.19(10)$ & $1.000(0)$ & & & \\
\hline OW1 & & & & & & $0.0719(20)$ & $0.4295(10)$ & $1.111(6)$ & $5.36(62)$ & $0.750(0)$ & & & \\
\hline OW2 & & & & & & $0.0000(0)$ & $0.6248(14)$ & $0.250(0)$ & $5.36(62)$ & $0.375(0)$ & & & \\
\hline \multirow[t]{3}{*}{ OW3 } & & & & & & $0.0000(0)$ & $0.4780(17)$ & $0.250(0)$ & $5.36(62)$ & $0.376(0)$ & & & \\
\hline & & & GRA225 & & & & & GRA25 & & & & & \\
\hline & $\mathrm{x}$ & $y$ & z & $B_{\text {iso }}$ & Occ & $\mathrm{x}$ & $y$ & $z$ & $B_{\text {iso }}$ & Occ & & & \\
\hline SI1 & $0.1990(7)$ & $0.0275(5)$ & $0.586(2)$ & $1.35(6)$ & $1.000(0)$ & $0.2005(9)$ & $0.0275(6)$ & $0.582(2)$ & $1.17(7)$ & $1.000(0)$ & & & \\
\hline $\mathrm{SI} 2$ & $0.2077(9)$ & $0.1405(3)$ & $0.569(2)$ & $1.35(6)$ & $1.000(0)$ & $0.2095(11)$ & $0.1413(5)$ & $0.577(2)$ & $1.17(7)$ & $1.000(0)$ & & & \\
\hline SI3 & $0.2100(9)$ & $0.1957(4)$ & $0.068(2)$ & $1.35(6)$ & $1.000(0)$ & $0.2061(10)$ & $0.1960(5)$ & $0.077(2)$ & $1.17(7)$ & $1.000(0)$ & & & \\
\hline Mg1 & $0.0000(0)$ & $0.0361(7)$ & $0.250(0)$ & $1.45(12)$ & $0.483(0)$ & $0.0000(0)$ & $0.0246(9)$ & $0.250(0)$ & $1.61(15)$ & $0.483(0)$ & & & \\
\hline Mg2 & $0.0000(0)$ & $0.0880(8)$ & $0.750(0)$ & $1.45(12)$ & $0.483(0)$ & $0.0000(0)$ & $0.0914(8)$ & $0.750(0)$ & $1.61(15)$ & $0.483(0)$ & & & \\
\hline Mg3 & $0.0000(0)$ & $0.1474(6)$ & $0.250(0)$ & $1.45(12)$ & $0.483(0)$ & $0.0000(0)$ & $0.1449(7)$ & $0.250(0)$ & $1.61(15)$ & $0.483(0)$ & & & \\
\hline Mg4 & $0.0000(0)$ & $0.1998(6)$ & $0.750(0)$ & $1.45(12)$ & $0.483(0)$ & $0.0000(0)$ & $0.2033(8)$ & $0.750(0)$ & $1.61(15)$ & $0.483(0)$ & & & \\
\hline 09 & $0.2500(0)$ & $0.2500(0)$ & $0.092(8)$ & $1.02(9)$ & $0.500(0)$ & $0.2500(0)$ & $0.2500(0)$ & $0.083(8)$ & $0.81(10)$ & $0.500(0)$ & & & \\
\hline 01 & $0.0901(13)$ & $0.0259(10)$ & $0.599(4)$ & $1.02(9)$ & $1.000(0)$ & $0.0820(16)$ & $0.0217(9)$ & $0.587(5)$ & $0.81(10)$ & $1.000(0)$ & & & \\
\hline $\mathrm{O} 3$ & $0.0803(16)$ & $0.1448(8)$ & $0.586(4)$ & $1.02(9)$ & $1.000(0)$ & $0.0660(17)$ & $0.1401(8)$ & $0.581(5)$ & $0.81(10)$ & $1.000(0)$ & & & \\
\hline O4 & $0.0745(15)$ & $0.1972(8)$ & $0.052(4)$ & $1.02(9)$ & $1.000(0)$ & $0.0947(16)$ & $0.1981(8)$ & $0.059(4)$ & $0.81(10)$ & $1.000(0)$ & & & \\
\hline O5 & $0.2506(13)$ & $0.0031(9)$ & $0.329(5)$ & $1.02(9)$ & $1.000(0)$ & $0.2645(17)$ & $0.0047(8)$ & $0.357(5)$ & $0.81(10)$ & $1.000(0)$ & & & \\
\hline $\mathrm{O} 6$ & $0.2498(13)$ & $0.0878(10)$ & $0.598(4)$ & $1.02(9)$ & $1.000(0)$ & $0.2498(15)$ & $0.0821(13)$ & $0.595(5)$ & $0.81(10)$ & $1.000(0)$ & & & \\
\hline $\mathrm{O} 7$ & $0.2800(15)$ & 0.1659(8) & $0.316(4)$ & $1.02(9)$ & $1.000(0)$ & $0.2639(18)$ & $0.1615(8)$ & $0.306(5)$ & $0.81(10)$ & $1.000(0)$ & & & \\
\hline $\mathrm{O} 8$ & $0.2699(15)$ & $0.1680(9)$ & $0.808(4)$ & $1.02(9)$ & $1.000(0)$ & $0.2994(16)$ & $0.1640(8)$ & $0.769(4)$ & $0.81(10)$ & $1.000(0)$ & & & \\
\hline $\mathrm{O} 2-\mathrm{OH}$ & $0.0744(12)$ & $0.0861(9)$ & $0.079(4)$ & $1.02(9)$ & $1.000(0)$ & $0.0879(13)$ & $0.0833(11)$ & $0.077(4)$ & $0.81(10)$ & $1.000(0)$ & & & \\
\hline O10-CW & $0.0859(13)$ & $0.2559(6)$ & $0.557(4)$ & $1.02(9)$ & $1.000(0)$ & $0.0712(17)$ & $0.2619(6)$ & $0.536(4)$ & $0.81(10)$ & $1.000(0)$ & & & \\
\hline OW1 & & & & & & $0.0635(21)$ & $0.4210(15)$ & $1.063(6)$ & $4.97(70)$ & $0.750(0)$ & & & \\
\hline OW2 & & & & & & $0.0000(0)$ & $0.6389(18)$ & $0.250(0)$ & $4.97(70)$ & $0.375(0)$ & & & \\
\hline \multirow[t]{3}{*}{ OW3 } & & & & & & $0.0000(0)$ & $0.4793(20)$ & $0.250(0)$ & $4.97(70)$ & $0.376(0)$ & & & \\
\hline & & & NOR225 & & & & & NOR25 & & & \multicolumn{3}{|c|}{ PREISINGER } \\
\hline & $\mathrm{x}$ & $y$ & $z$ & $B_{\text {iso }}$ & Occ & $x$ & $y$ & $z$ & $B_{\text {iso }}$ & Occ & $x$ & $y$ & $z$ \\
\hline SI1 & $0.2016(4)$ & $0.0283(3)$ & $0.585(1)$ & $1.24(3)$ & $1.000(0)$ & $0.1990(4)$ & $0.0272(3)$ & $0.583(1)$ & $0.63(3)$ & $1.000(0)$ & 0.208 & 0.028 & 0.563 \\
\hline $\mathrm{SI} 2$ & $0.2054(6)$ & $0.1410(2)$ & $0.571(1)$ & $1.24(3)$ & $1.000(0)$ & $0.2091(5)$ & $0.1405(2)$ & $0.574(1)$ & $0.63(3)$ & $1.000(0)$ & 0.208 & 0.140 & 0.563 \\
\hline SI3 & $0.2026(5)$ & $0.1961(2)$ & $0.075(1)$ & $1.24(3)$ & $1.000(0)$ & $0.2003(5)$ & $0.1967(2)$ & $0.080(1)$ & $0.63(3)$ & $1.000(0)$ & 0.208 & 0.196 & 0.063 \\
\hline Mg1 & $0.0000(0)$ & $0.0314(5)$ & $0.250(0)$ & $1.07(5)$ & $0.480(0)$ & $0.0000(0)$ & $0.0300(5)$ & $0.250(0)$ & $0.75(6)$ & $0.480(0)$ & 0.000 & 0.028 & 0.250 \\
\hline Mg2 & $0.0000(0)$ & $0.0883(4)$ & $0.750(0)$ & $1.07(5)$ & $0.480(0)$ & $0.0000(0)$ & $0.0887(4)$ & $0.750(0)$ & $0.75(6)$ & $0.480(0)$ & 0.000 & 0.084 & 0.750 \\
\hline Mg3 & $0.0000(0)$ & $0.1465(3)$ & $0.250(0)$ & $1.07(5)$ & $0.480(0)$ & $0.0000(0)$ & $0.1451(4)$ & $0.250(0)$ & $0.75(6)$ & $0.480(0)$ & 0.000 & 0.140 & 0.250 \\
\hline Mg4 & $0.0000(0)$ & $0.2021(3)$ & $0.750(0)$ & $1.07(5)$ & $0.480(0)$ & $0.0000(0)$ & $0.2041(4)$ & $0.750(0)$ & $0.75(6)$ & $0.480(0)$ & 0.000 & 0.196 & 0.750 \\
\hline 09 & $0.2500(0)$ & $0.2500(0)$ & $0.079(4)$ & $1.17(4)$ & $0.500(0)$ & $0.2500(0)$ & $0.2500(0)$ & $0.077(4)$ & $0.48(5)$ & $0.500(0)$ & 0.250 & 0.250 & 0.063 \\
\hline $\mathrm{O} 1$ & $0.0850(8)$ & $0.0283(7)$ & $0.596(2)$ & $1.17(4)$ & $1.000(0)$ & $0.0900(8)$ & $0.0257(5)$ & $0.566(2)$ & $0.48(5)$ & $1.000(0)$ & 0.084 & 0.028 & 0.563 \\
\hline $\mathrm{O} 3$ & $0.0787(9)$ & $0.1430(5)$ & $0.578(2)$ & $1.17(4)$ & $1.000(0)$ & $0.0730(9)$ & $0.1399(4)$ & $0.583(2)$ & $0.48(5)$ & $1.000(0)$ & 0.084 & 0.140 & 0.563 \\
\hline O4 & $0.0869(8)$ & $0.1980(4)$ & $0.057(2)$ & $1.17(4)$ & $1.000(0)$ & $0.0819(9)$ & $0.1963(4)$ & $0.086(2)$ & $0.48(5)$ & $1.000(0)$ & 0.084 & 0.196 & 0.063 \\
\hline O5 & $0.2463(7)$ & $0.0031(5)$ & $0.331(3)$ & $1.17(4)$ & $1.000(0)$ & $0.2535(8)$ & $0.0065(5)$ & $0.332(3)$ & $0.48(5)$ & $1.000(0)$ & 0.240 & 0.000 & 0.313 \\
\hline $\mathrm{O} 6$ & $0.2436(6)$ & $0.0877(6)$ & $0.602(2)$ & $1.17(4)$ & $1.000(0)$ & $0.2401(7)$ & $0.0791(5)$ & $0.601(2)$ & $0.48(5)$ & $1.000(0)$ & 0.240 & 0.084 & 0.563 \\
\hline $\mathrm{O} 7$ & $0.2512(8)$ & $0.1669(5)$ & $0.318(3)$ & $1.17(4)$ & $1.000(0)$ & $0.2444(9)$ & $0.1664(5)$ & $0.335(3)$ & $0.48(5)$ & $1.000(0)$ & 0.240 & 0.168 & 0.313 \\
\hline $\mathrm{O} 8$ & $0.2642(7)$ & $0.1712(4)$ & $0.794(2)$ & $1.17(4)$ & $1.000(0)$ & $0.2621(8)$ & $0.1700(5)$ & $0.776(2)$ & $0.48(5)$ & $1.000(0)$ & 0.240 & 0.168 & 0.813 \\
\hline $\mathrm{O} 2-\mathrm{OH}$ & $0.0846(7)$ & $0.0846(6)$ & $0.084(2)$ & $1.17(4)$ & $1.000(0)$ & $0.0862(7)$ & $0.0835(5)$ & $0.093(2)$ & $0.48(5)$ & $1.000(0)$ & 0.084 & 0.084 & 0.063 \\
\hline O10-CW & $0.0807(8)$ & $0.2583(3)$ & $0.561(2)$ & $1.17(4)$ & $1.000(0)$ & $0.0781(8)$ & $0.2611(4)$ & $0.557(2)$ & $0.48(5)$ & $1.000(0)$ & 0.083 & 0.250 & 0.500 \\
\hline oW1 & & & & & & $0.0631(11)$ & $0.3923(7)$ & $0.999(3)$ & $5.31(46)$ & $0.750(0)$ & 0.083 & 0.416 & 0.917 \\
\hline OW2 & & & & & & $0.0000(0)$ & $0.6374(9)$ & $0.250(0)$ & $5.31(46)$ & $0.375(0)$ & 0.000 & 0.672 & 0.250 \\
\hline OW3 & & & & & & $0.0000(0)$ & $0.4851(11)$ & $0.250(0)$ & $5.31(46)$ & $0.375(0)$ & 0.000 & 0.485 & 0.250 \\
\hline
\end{tabular}

Note: Data from Brauner and Preisinger (1956) are also included as reference.

BAT. Although the final refinement parameters may not look as good as in Post et al. (2007), our refinements include the main (110) peak, in contrast to Post et al. (2007). The changes in cell parameters when increasing temperature from 25 to $225^{\circ} \mathrm{C}$ show that the $a$ parameter reduces by $0.35 \%$ in BAT, $0.24 \%$ in GRA, and $0.23 \%$ in NOR, compared with $0.45 \%$ in Post et al. (2007). The lattice change in the $a$ direction is larger than in $b$ [increase of $0.31 \%$ in BAT, $0.17 \%$ in GRA, $0.22 \%$ in NOR, and $0.20 \%$ in Post et al. (2007)]. There is almost no change in $c$. The release of zeolitic $\mathrm{H}_{2} \mathrm{O}$ liberates space in the tunnels producing a reduction of the unit-cell volume [0.02\% in BAT, $0.11 \%$ in GRA, $0.03 \%$ in NOR, and $0.16 \%$ in Post et al. (2007)] that masked the thermal expansion by heating. The number of zeolitic $\mathrm{H}_{2} \mathrm{O}$ molecules for half-unit has been fixed to 6 for the refinements, but the posi- 
tions have been refined. The atomic positions have been refined starting from those of the dehydrated samples. Their positions are quite stable, with very small changes for tetrahedral and octahedral centers $(0.005 \pm 0.003 \AA)$ and larger for oxygen $(0.023 \pm$ $0.017 \AA$ ). Some details present in the dehydrated pattern are not shown in the ambient pattern, like the tiny (020) peak resolved in NOR225, and hidden under the main (110) peak for the others.

\section{D X-ray microdiffraction}

One of the drawbacks of structural studies on clay minerals is the difficulty to perform X-ray diffraction on single crystals, as (by definition) clay grains are smaller than $2 \mu \mathrm{m}$. The powder diffraction methods are very efficient, but rely on the average composition of the studied sample. Apart from the compositional variability of sepiolite as a function of the origin, there is also a natural variability among samples coming from the same provenance, and even from different sections of the very same sample. Electron diffraction techniques are not yet well developed for structural refinements in clays, and will be discussed in the next paragraph. On the contrary, single-crystal X-ray diffraction is a mature technique, whose application increased with the use of synchrotron radiation sources. The use of monochromatic beams of micrometer and sub-micrometer dimensions made the study of very small microcrystals possible. The use of 2D detectors permits the visualization of sample inhomogeneities, providing textural and orientational information spatially resolved. However, the main difficulties are related to the availability of micrometer and sub-micrometer X-ray beams as well as the sample preparation and manipulation. As an example, Pluth et al. (1997) deciphered the crystalline structure of raite, a rare modulated silicate featuring tunnels in its structure (similar to sepiolite) using a synchrotron radiation microbeam and singlecrystal diffraction.

Here, we have selected some samples for microbeam diffraction acquisitions using synchrotron radiation at ESRF/ID18F beamline. The images were collected using a monochromatic beam (14440 eV or $0.86 \AA$ ) in transmission geometry, using a flat camera at about $114 \mathrm{~mm}$ from the sample. A bunch of fibers from two macroscopic sepiolites (NOR and HEN) were measured directly using the microbeam, while others belonging to the clay sepiolite group (like BAT) were powdered and placed in glass capillaries. A visible light microscope was used to monitor the positioning of the fibers in the X-ray microbeam.

Figure 6 a shows the 2D diffraction patterns for a clay sepiolite (BAT). The continuity and symmetry of the well-defined DebyeScherrer rings reveal the homogeneity of this sample considered as a real powder, because the grains are smaller than the beam size. The X-ray microbeam (about $2 \times 5 \mu \mathrm{m}^{2}$ cross section) illuminates a large amount of grains, contributing all of them to the diffraction pattern. However, there are some intense spikes in the diffraction pattern that correspond to single-crystal diffraction of individual large grains. The radial intensity, obtained by azimuthal integration of the full image, gives the diffraction pattern, which is overlaid to the diffraction image.

In Figure 6b, the 2D diffraction image of a macroscopic sepiolite (HEN) displays a drastically different pattern. The lack of cylindrical symmetry reflects a preferential orientation of the particles (fibers). The pattern roughly shows a four-quadrant

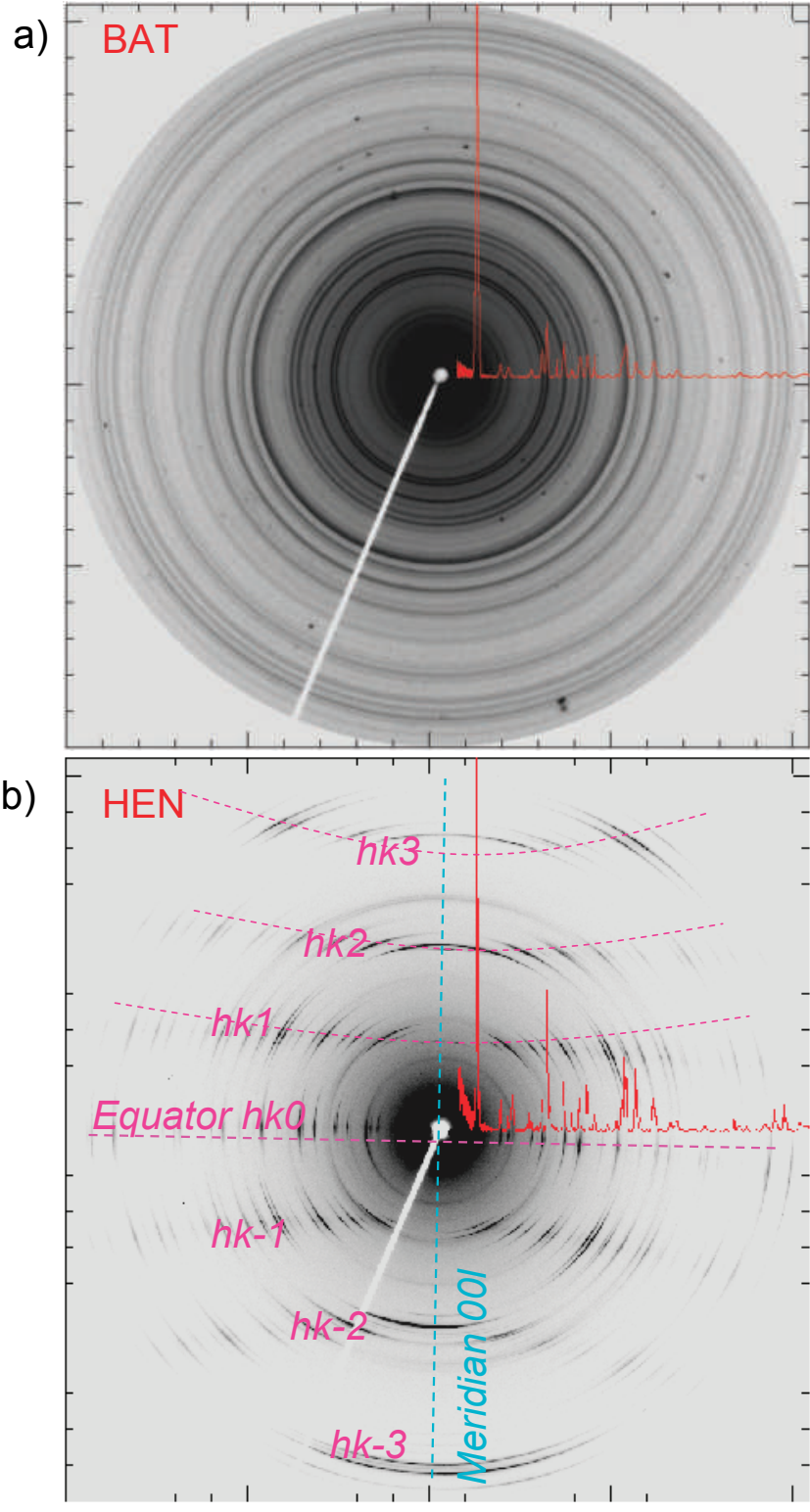

FIGURE 6. 2D diffraction patterns for (a) a clay sepiolite BAT and (b) a macroscopic sepiolite HEN. The overlaid diffraction patterns are calculated from azimuthal integration of the $2 \mathrm{D}$ patterns.

symmetry, as typical from ideal fiber diffraction. The bunch of fibers illuminated by the microbeam are orientated in such a way that the $c$ axis is perpendicular to the beam. The equator of the image plate is the symmetry axis of the image and contains the ( $h k 0)$ reflections. The perpendicular direction (meridian axis) contains the $(00 l)$ reflections. There are lines running almost parallel to the equator, which correspond to the ( $h k \pm 1),(h k \pm 2)$, $(h k \pm 3)$, etc. reflections. These lines follow hyperbolas, as a consequence of the finite radius of the Ewald sphere. From the diffraction pattern overlaid in Figure $6 \mathrm{~b}$ some changes in the intensity of several peaks with respect to the clay sepiolite (Fig. 6a) may be observed because of the preferred orientations of the crystallites. The image looks symmetric with respect to the meridian, but slightly asymmetry with respect to the equator, in 

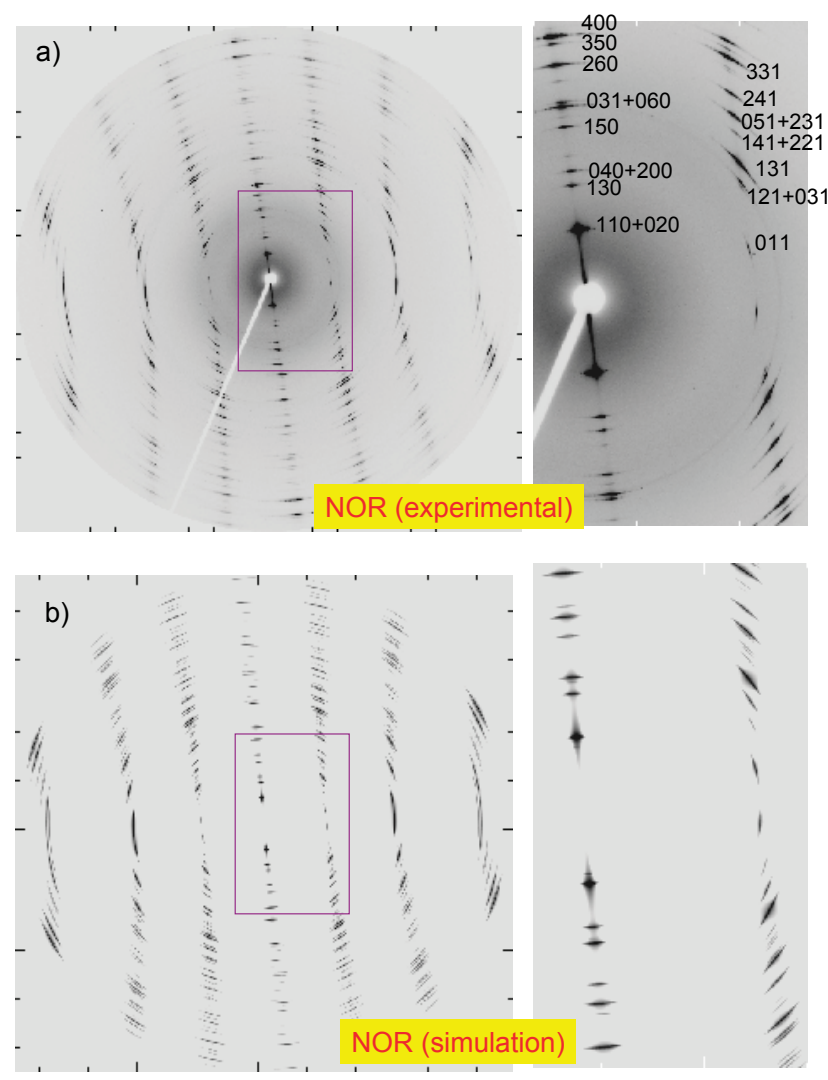

FIGURE 7. 2D diffraction patterns for NOR sepiolite. (a) Experimental pattern and (b) simulated image (see text).

particular at the $(h k \pm 2)$ lines. The reason is that the fiber axis and the incident beam are not exactly perpendicular to each other.

Among all the samples analyzed in this work, NOR presents a higher crystallinity, producing better defined and textured images. Figure 7 shows a comparison of the experimental pattern with an ab initio simulation using the ANAELU software (Fuentes-Montero et al. 2011) for a polycrystalline sepiolite. It calculates the 2D diffraction pattern of a crystal with axial texture starting from the inverse pole figure (IPF). The program computes the intensities of all possible reflections up to a maximum ( $h k l)$ (set to 888 in our case), and builds the 2D diffraction pattern from all direct pole figures (DPF) derived from the IPF. The 2D diffraction profile for sepiolite is shown in Figure 7b, calculated from the Rietveld refined structure. It exhibits an excellent agreement with the experimental one. This finding has two meanings: on one hand, the use of a $2 \times 5 \mu \mathrm{m}^{2}$ beam size is experimentally well adapted to the illumination of a single bunch of sepiolite fibers of this macroscopic sepiolite, as it seems evident from the SEM images on Figure 2. On the other hand, the algorithm used in the simulation reproduces qualitatively the full experimental image, making it useful for quantitative analysis, like refining the crystalline structure including textural analysis. The diffraction patterns of NOR are very detailed and many reflections can be individually resolved. The details of some $(h k 0)$ and $(h k 1)$ peaks and their indexation are also shown in Figure 7. The simulations are computationally very intensive (the simulation presented here run for several hours on a laptop
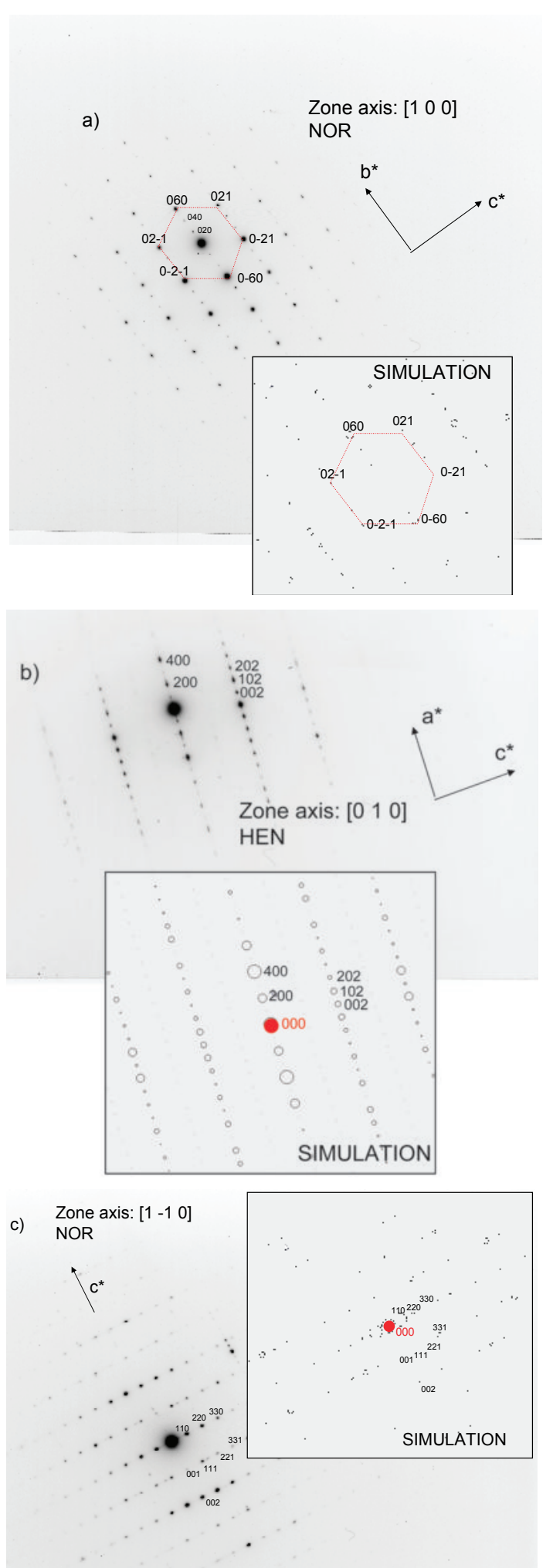

FIGURE 8. Experimental and simulated ED patterns for two macroscopic sepiolites (HEN and NOR) along three different zone axes.

computer), and it will be necessary to speed up the calculation and probably use parallel computing for being able to refine parameters. This technique is well adapted for fibrous clays of the sepiolite-palygorskite group. The microbeam used was able 
to see the fiber structure for the most macroscopic sepiolites, but with the X-ray nanobeams that will be available soon (e.g., in the context of the ESRF Upgrade Programme), it will be possible to study clays with smaller fibers. In parallel, we will address the issue of crystallographic refinement of $2 \mathrm{D}$ textured patterns in a future publication.

\section{Electron diffraction}

Electron diffraction (ED) from TEM data of a nanosized single crystals is a valuable technique for the qualitative structural characterization at microscopic levels. Two experimental modes are used to obtain ED patterns: (1) high-resolution TEM (HRTEM) images in real space with at least nanometric resolution from which the electron diffraction patterns are obtained via Fourier transform, and (2) selected area electron diffraction (SAED) where the diffraction pattern is recorded directly in reciprocal space. Recently, ED was used to complement X-ray powder diffraction for quantitative structure determination of zeolites (Baerlocher et al. 2007; Gramm et al. 2006). However, these methods still present some experimental difficulties, partially solved by using precession electron diffraction (Oleynikov et al. 2007), and the lack of accurate electron-matter scattering factors. In spite of that, ED helped in the determination of sepiolite crystalline structure since the early days: Brindley (1959) reported ED images from a clay sepiolite and well-crystallized fibers of sepiolite, stressing the excellent single-crystal diagrams of the latter. Rautureau et al. (Rautureau and Tchoubar 1972; Rautureau et al. 1972) found differences in the position and occupation of some atoms with respect to the B\&P model. The main problem concerning ED images of sepiolite is the radiation damage. The sepiolite structure under the high-power density of the electron beam is quickly dehydrated and destroyed in a few seconds. Despite this strong inconvenience, it might be possible to obtain good SAED images in some cases. Figure 8 shows the best-recorded SAED images chosen from tens of images of all sepiolites studied. They correspond to the macroscopic sepiolites HEN and NOR. The experimental images are accompanied by simulated images computed using the JECD/ED software ( $\mathrm{Li}$ 2003). There is a very good agreement in the position of the peaks and in the overall pattern, allowing the identification of the zone axes [100], [010], and [110] in the images represented in Figure 8. These axes are always perpendicular to the fiber direction $<001>$, as expected intuitively from the arrangement of sticks in a plane. Moreover, the comparison between simulation and experiment helped us in the indexation of the experimental images, suggesting, as in the case of X-ray fiber diffraction, the possibility to use ED images for solving and refining clay structures by a quantitative analysis.

\section{ACKNOWLEDGMENTS}

Financial support by CICYT (project CGL2009-10764) is acknowledged. We acknowledge the ESRF for beamtime. We thank the staff of BM25 (SPLINE) for support and discussions. We are indebt with Juan Rodriguez-Carvajal for discussions and suggestions related to the Rietveld refinements.

\section{REFERENCES CITED}

Alkan, M., Demirbas, Ö., and Dogan, M. (2007) Adsorption kinetics and thermodynamics of an anionic dye onto sepiolite. Microporous and Mesoporous Materials, 101, 388-396.

Arranz, E., Lago, M., Bastida, J., Galé, C., Soriano, J., and Ubide, T. (2008)
Hydrothermal macroscopic Fe-sepiolite from Oujda Mounts (Middle Atlas, Eastern Morocco). Journal of African Earth Sciences, 52, 81-88.

Baerlocher, C., Gramm, F., Massuger, L., McCusker, L.B., He, Z., Hovmoller, S., and Zou, X. (2007) Structure of the polycrystalline zeolite catalyst IM-5 solved by enhanced charge flipping. Science, 315, 1113-1116.

Bastida, J., Besteiro, J., Lago, M., Pocovi, A., and Reventos, M. (1994) Occurrence of fibrous sepiolite in alkaline basalt in the Valley of Alfara (Baix Ebre, Tarragona, Spain). Clay Minerals, 29, 137-142.

Brauner, K. and Preisinger, A. (1956) Struktur und Entstehung des Sepioliths. Mineralogy and Petrology, 6, 120-140.

Brindley, G.W. (1959) X-ray and electron diffraction data for sepiolite. American Mineralogist, 44, 495-500.

Callen, R.A. (1984) Clays of the paligorskite-sepiolite group: depositional environment, age and distribution. In A. Singer and E. Galán, Eds., Palygorskite-sepiolite: Occurrences, Genesis and Uses. Developments in Sedimentology, vol. 37, p. 1-38. Elsevier, Amsterdam.

Casal, B., Merino, J., Serratosa, J.-M., and Ruiz-Hitzky, E. (2001) Sepiolite-based materials for the photo- and thermal-stabilization of pesticides. Applied Clay Science, $18,245-254$

Chryssikos, G.D., Gionis, V., Kacandes, G.H., Stathopoulou, E.T., Suárez, M., García-Romero, E., and Sánchez del Río, M. (2009) Octahedral cation distribution in palygorskite. American Mineralogist, 94(1), 200-203.

Favre-Nicolin, V. and Cerny, R. (2002) FOX, "free objects for crystallography": A modular approach to ab initio structure determination from powder diffraction. Journal of Applied Crystallography, 35, 734-743.

Finger, L.W., Cox, D.E., and Jephcoat, A.P. (1994) A correction for powder diffraction peak asymmetry due to axial divergence. Journal of Applied Crystallography, 27, 892-900.

Frost, R.L. and Ding, Z. (2003) Controlled rate thermal analysis and differentia scanning calorimetry of sepiolites and palygorskites. Thermochimica Acta, 397, 119-128.

Fuentes-Montero, L., Montero-Cabrera, M.E., and Fuentes-Cobas, L. (2011) Software ANAELU for 2D X-ray diffraction analysis. Journal of Applied Crystallography, 44, 241-246.

García-Romero, E. and Suárez, M. (2010) On the chemichal composition of sepiolite and palygorskite. Clays and Clay Minerals, 58, 1-20.

Gómez-Avilés, A., Darder, M., Aranda, P., and Ruiz-Hitzky, E. (2010) Multifunctional materials based on graphene-like/sepiolite nanocomposites. Applied Clay Science, 47, 203-211.

Gramm, F., Baerlocher, C., McCusker, L.B., Warrender, S.J., Wright, P.A., Han, B., Hong, S.B., Liu, Z., Ohsuna, T., and Terasaki, O. (2006) Complex zeolite structure solved by combining powder diffraction and electron microscopy. Nature, 444, 79-81.

Janeba, D., Capkova, P., Weiss, Z., and Schenk, H. (1998) XRD profile analysis of clay minerals. Materials Science Forum, 278-281, 139-144.

Legido, J.L., Medina, C., Lourdes Mourelle, M., Carretero, M.I., and Pozo, M. (2007) Comparative study of the cooling rates of bentonite, sepiolite and common clays for their use in pelotherapy. Applied Clay Science, 36, 148-160.

Li, X.Z. (2003) JECP/ED - a computer program for simulation of selected-area and precesion electron diffraction pattern. Journal of Applied Crystallography, $36,956$.

Molina-Sabio, M., Caturla, F., Rodríguez-Reinoso, F., and Kharitonova, G.V (2001) Porous structure of a sepiolite as deduced from the adsorption of $\mathrm{N}_{2}$, $\mathrm{CO}_{2}, \mathrm{NH}_{3}$ and $\mathrm{H}_{2} \mathrm{O}$. Microporous and Mesoporous Materials, 47, 389-396.

Nagy, B. and Bradley, W.F. (1955) The structural scheme of sepiolite. American Mineralogist, 40, 885-892.

Oleynikov, P., Hovmöller, S., and Zou, X.D. (2007) Precession electron diffraction: Observed and calculated intensities. Ultramicroscopy, 107, 523-533.

Pardo, P., Bastida, J., Serrano, F.J., Ibanez, R., and Kojdecki, M.A. (2009) X-ray diffraction line-broadening study on two vibrating, dry-milling procedures in kaolinites. Clays and Clay Minerals, 57, 25-34.

Pluth, J.J., Smith, J.V., Pushcharovsky, D.Y., Semenov, E.I., Bram, A., Riekel, C., Weber, H.-P., and Broach, R.W. (1997) Third-generation synchrotron X-ray diffraction of 6 - $\mu \mathrm{m}$ crystal of raite, $\approx \mathrm{Na}_{3} \mathrm{Mn}_{3} \mathrm{Ti}_{0.25} \mathrm{Si}_{8} \mathrm{O}_{20}(\mathrm{OH})^{2} \cdot 10 \mathrm{H}_{2} \mathrm{O}$, opens up new chemistry and physics of low-temperature minerals. Proceedings of the National Academy of Sciences, 94, 12263-12267.

Post, J.E., Bish, D.L., and Heaney, P.J. (2007) Synchrotron powder X-ray diffraction study of the structure and dehydration behavior of sepiolite. American Mineralogist, 92, 91-97.

Preisinger, A. (1959) X-ray study of the structure of sepiolite. Clays and Clay Minerals, 6, 61-67.

Rautureau, M. and Tchoubar, C. (1972) Précisions concernant l'analyse structurale de la sépiolite par microdiffraction électronique. Comptes Rendues Hebdomadaires Académie des Sciences de Paris, 278B, 25-28.

Rautureau, M., Tchoubar, C., and Mering, J. (1972) Analyse structurale de la sépiolite par micro-diffraction électronique. Comptes Rendues de l'Academie des Sciences, Paris, 274, C-269-271.

Rodriguez-Carvajal, J. (1993) Recent advances in magnetic structure determination by neutron powder diffraction. Physica B, 192, 55-69. 
Roisnel, T. and Rodriguez-Carvajal, J. (2000) WinPLOTR: a Windows tool for powder diffraction patterns analysis. In R. Delhez, and E.J. Mittenmeijer, Eds. Materials Science Forum, Proceedings of the Seventh European Powder Diffraction Conference (EPDIC 7).

Sánchez del Río, M. and Dejus, R.J. (2004) XOP 2.1-A new version of the X-ray optics software toolkit. American Institute of Physics, Conference Proceedings, 705, 784.

Sanchez-Martin, M.J., Rodriguez-Cruz, M.S., Andrades, M.S., and SanchezCamazano, M. (2006) Efficiency of different clay minerals modified with a cationic surfactant in the adsorption of pesticides: Influence of clay type and pesticide hydrophobicity. Applied Clay Science, 31, 216-228.

Serna, C., Ahlrichs, J.L., and Serratosa, J.M. (1975) Folding in sepiolite crystals. Clays and Clay Minerals, 23, 452-457.

Somogyi, A., Drakopoulos, M., Vincze, L., Vekemans, B., Camerani, C., Janssens, K., Snigirev, A., and Adams, F. (2001) ID18F: a new micro-X-ray fluorescence end-station at the European Synchrotron Radiation Facility (ESRF): preliminary results. X-Ray Spectrometry, 30, 242-252.

Stathopoulou, E.T., Suárez, M., García-Romero, E., Sánchez del Río, M., Kacandes, G.H., Gionis, V., and Chryssikos, G.D. (2011) Trioctahedral entities in palygorskite: Near infrared evidence for sepiolite-palygorskite polysomatism. European Journal of Mineralogy, in press.

Suárez, M., García-Romero, E., and Sánchez del Río, M. (2010) Structure and
Composition of Sepiolite. In J. Cuevas, J.F. Barrenechea, E. García-Romero, S. Leguey, and J. Luque, Eds. 2010 SEA-CSSJ-CMS Trilateral Meeting on Clays. Field Trip guide and Abstracts of the Sepiolite Symposium, p. 51-54, Madrid. Suárez, M., García-Romero, E., Sánchez del Río, M., Martinetto, P., and Dooryhee, E. (2007) The effect of the octahedral cations on the dimensions of the palygorskite cell. Clay Minerals, 42, 287-297.

Viani, A., Gualtieri, A.F., and Artioli, G. (2002) The nature of disorder in montmorillonite by simulation of X-ray powder patterns. American Mineralogist, $87,966-975$.

Vico, L.I. and Acebal, S.G. (2006) Some aspects about the adsorption of quinoline on fibrous silicates and Patagonian saponite. Applied Clay Science, 33 $142-148$.

Yalcin, H. and Bozkaya, O. (1995) Sepiolite-palygorskite from the Hekimhan region (Turkey). Clays and Clay Minerals, 43, 705-717.

(2004) Ultramafic-rock-hosted vein sepiolite occurrences in the Ankara Ophiolitic Melange, Central Anatolia, Turkey. Clays and Clay Minerals, 52, 227-239.

MANUSCRIPT RECEIVED DECEMBER 10, 2010

MANUSCRIPT ACCEPTED JUNE 14, 2011

MANUSCRIPT HANDLED BY WARREN HUFF 